\title{
Scaffold-Based Tissue Engineering Strategies for Osteochondral Repair
}

OPEN ACCESS

Edited by:

Yin Fang,

Nanyang Technological University,

Singapore

Reviewed by:

Jianxun Ding,

Changchun Institute of Applied

Chemistry (CAS), China

Yongliang $\mathrm{Ni}$,

Lam Research, United States

Zhen Yang,

Nankai University, China

Wenguo Cui,

Shanghai Jiao Tong University, China

${ }^{*}$ Correspondence:

Jia-Kuo Yu

yujiakuo@126.com

Fu-Zhen Yuan

yuanfuzhen2016@163.com

${ }^{+}$These authors have contributed equally to this work

Specialty section: This article was submitted to Biomaterials,

a section of the journal Frontiers in Bioengineering and

Biotechnology

Received: 10 November 2021 Accepted: 16 December 2021 Published: 11 January 2022

Citation:

Fu J-N, Wang $X$, Yang $M$, Chen $Y$-R, Zhang J-Y, Deng R-H, Zhang Z-N, Yu $J-K$ and Yuan F-Z (2022) ScaffoldBased Tissue Engineering Strategies for Osteochondral Repair. Front. Bioeng. Biotechnol. 9:812383. doi: 10.3389/fbioe.2021.812383
Jiang-Nan $\mathrm{Fu}^{1,2 \dagger}$, Xing Wang ${ }^{3,4 t}$, Meng Yang ${ }^{1,2 \dagger}$, You-Rong Chen ${ }^{1,2}$, Ji-Ying Zhang ${ }^{1,2}$, Rong-Hui Deng ${ }^{1,2}$, Zi-Ning Zhang ${ }^{1,2}$, Jia-Kuo $\mathrm{Yu}^{1,2 *}$ and Fu-Zhen Yuan ${ }^{1,2 *}$

${ }^{1}$ Department of Sports Medicine, Peking University Third Hospital, Beijing, China, ${ }^{2}$ Institute of Sports Medicine of Peking University, Beijing, China, ${ }^{3}$ Beijing National Laboratory for Molecular Sciences, State Key Laboratory of Polymer Physics and Chemistry, Institute of Chemistry, Chinese Academy of Sciences, Beijing, China, ${ }^{4}$ University of Chinese Academy of Sciences, Beijing, China

Over centuries, several advances have been made in osteochondral (OC) tissue engineering to regenerate more biomimetic tissue. As an essential component of tissue engineering, scaffolds provide structural and functional support for cell growth and differentiation. Numerous scaffold types, such as porous, hydrogel, fibrous, microsphere, metal, composite and decellularized matrix, have been reported and evaluated for $\mathrm{OC}$ tissue regeneration in vitro and in vivo, with respective advantages and disadvantages. Unfortunately, due to the inherent complexity of organizational structure and the objective limitations of manufacturing technologies and biomaterials, we have not yet achieved stable and satisfactory effects of $\mathrm{OC}$ defects repair. In this review, we summarize the complicated gradients of natural $O C$ tissue and then discuss various osteochondral tissue engineering strategies, focusing on scaffold design with abundant cell resources, material types, fabrication techniques and functional properties.

Keywords: osteochondral repair, scaffolds, fabrication, tissue engineering, biomaterials

\section{INTRODUCTION}

The management and repair of osteochondral (OC) defects are still one of the most challenging clinical issues in orthopedics. Resulting from trauma, athletic injury or pathological factors, early localized osteochondral lesions can lead to general tissue deterioration, characterized clinically by severe pain and functional incapacitation of the affected joints (Hunter and Bierma-Zeinstra, 2019). As a common degenerative disease worldwide with high socioeconomic burdens, osteoarthritis (OA) is an adverse outcome of OC defects (Kwon et al., 2019). At the same time, OA can exacerbate the defects as a major cause. By 2030, approximately 67 millions people are expected to suffer from OA in the United States (Murphy and Helmick, 2012; Zhao et al., 2019). The upper articular cartilage possesses a stratified structure with no lymphatic or vascular components, lacking the capability of self-rehabilitation (Le et al., 2021). Moreover, different gradients of OC tissue have heterogeneous microstructures and biological properties (Ansari et al., 2019). So far, various clinical treatments have been available to alleviate symptoms and improve life quality to some extent, including microfracture technology, mosaicplasty, subchondral drilling, chondral shaving, abrasion arthroplasty, auto/allografts and joint replacement surgery (Redman et al., 2005; Gracitelli et al., 2016). Unfortunately, on account of the complex condition involving different layers of articular cartilage, cartilage-bone interface and subchondral bone, all these approaches have failed to achieve complete repair of OC defects and satisfactory reconstruction of joint functions. Then, the emergence of tissue engineering strategies has shown promise as a potential alternative for OC defect repair (Smith and Grande, 2015). This review aims to update the 


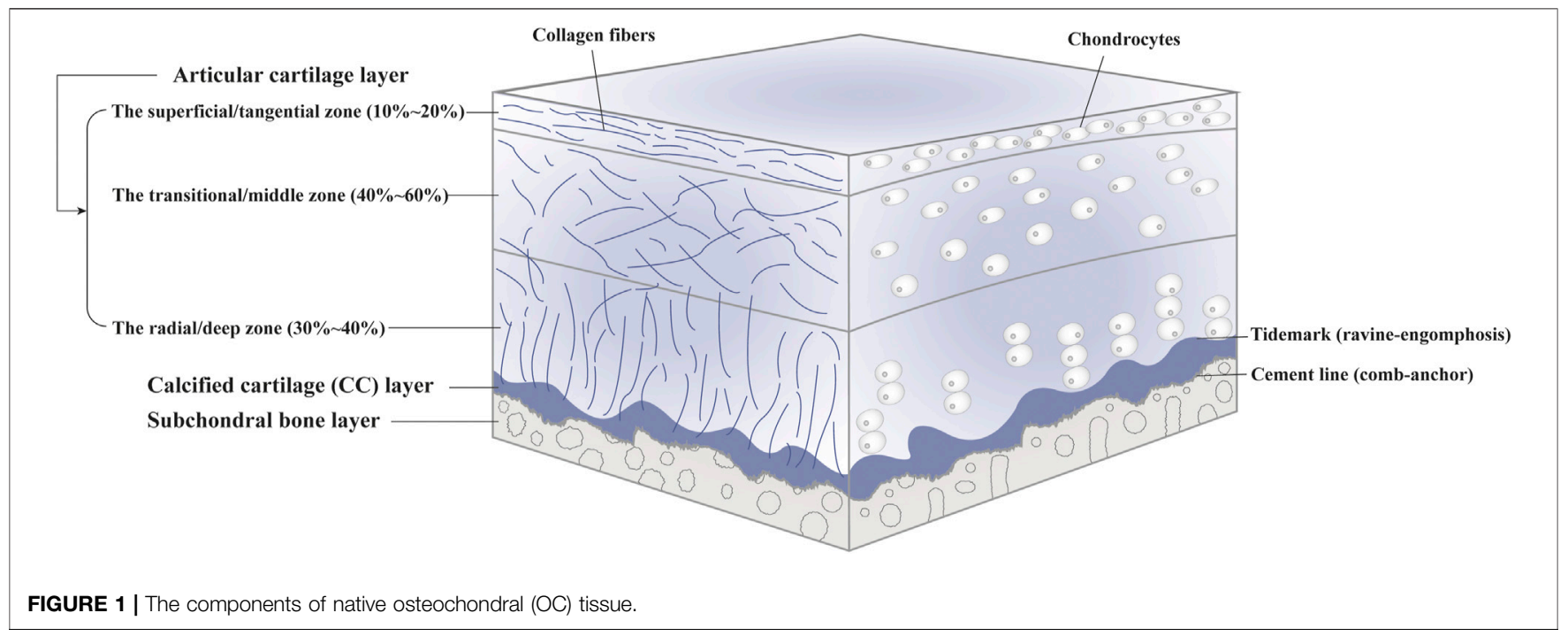

recent development in OC tissue engineering, focusing on biomaterial design and scaffold modification.

\section{NATIVE OSTEOCHONDRAL TISSUE: STRUCTURE AND TISSUE ENGINEERING}

\section{Articular Cartilage}

As a tough and flexible connective tissue lack of lymphatics, blood vessels and nerves, articular cartilage can be further divided into the radial/deep zone, the transitional/middle zone and the superficial/tangential zone, consisting of embedded chondrocytes and extracellular matrix (ECM) (Hunziker et al., 2002; Sophia Fox et al., 2009) (Figure 1). As the singular cell type, chondrocytes are responsible for the synthesis, homeostasis and remodeling of ECM. Also, they can sense local environment by expressing integrins (Loeser, 2014). Each chondrocyte and the surrounded narrow pericellular matrix $(\mathrm{PCM})$ is referred to as a chondron (Poole et al., 1987). With tensile strength and unique viscoelastic properties, articular cartilage facilitates load transmission to subchondral bone during compression and restores original appearance when the pressure is relieved, performed by the fibrillar collagen network and entrapped macromolecules such as collagen II and proteoglycans in the ECM (Carballo et al., 2017). In addition, articular cartilage provides a lubricated surface to reduce friction with the presence of lubricin and hyaluronic acid. In terms of nutritional supplies, on the one hand, joint movement and mechanical stimulation cause synovial fluid to flow over the cartilage surface. On the other hand, small molecules can penetrate from subchondral bone into articular cartilage through potential direct signaling pathways (Pan et al., 2009). Signals associated with cartilage injury or scaffold implantation can recruit and activate immune cells, followed by cellular polarization. The phenotypes of cells and their interactions can affect the local microenvironment. Pro-regenerative microenvironment can develop proper tissue resembling the original host tissue; however, unbalanced immune system can produce inflammation and fibrocartilage, causing functional impairment (Sadtler et al., 2016).

\section{Calcified Cartilage}

The calcified cartilage (CC) layer is defined as mineralized cartilage between articular cartilage layer and subchondral bone plate which passages from the so-called tidemark to the cement line (Ferguson et al., 2003; Lyons et al., 2006). The CC layer interlocked tightly with the upper articular cartilage and the lower subchondral bone plate in the manner of "ravineengomphosis" and "comb-anchor", respectively, (Wang et al., 2009) (Supplementary Figure S1). The undulated interface helps convert shear into compressive and tensile forces. Also, it can provide an integration to transfer mechanical load between flexible cartilage and stiff subchondral bone and maintain interfacial environment (Goldring and Goldring, 2016).

\section{Subchondral Bone}

Subchondral bone refers to the bony layer beneath the cement line, which can be anatomically divided into subchondral bone plate (SBP) and trabecular bone (STB) (Goldring and Goldring, 2010). SBP is impenetrable cortical lamellae, whereas STB is more porous and metabolically active with lower volume, density and stiffness. Osteocytes, the most widely distributed cell throughout bone tissue, are involved in bone metabolism and mechanical transduction through solid matrix directly or load-induced fluid flow indirectly (Knothe Tate et al., 2004; Furuya et al., 2018). Collagen I accounts for over $90 \%$ of bone matrix (Blair et al., 2017; Schlesinger et al., 2020). The environment in subchondral bone has an effect on the viscoelasticity and nutritional metabolism of articular cartilage (Burr and Gallant, 2012; Fell et al., 2019; Hu et al., 2021).

\section{Gradients of the OC Tissue}

Distinct gradients and properties during development and maturation, with regard to biochemistry, mechanics, 


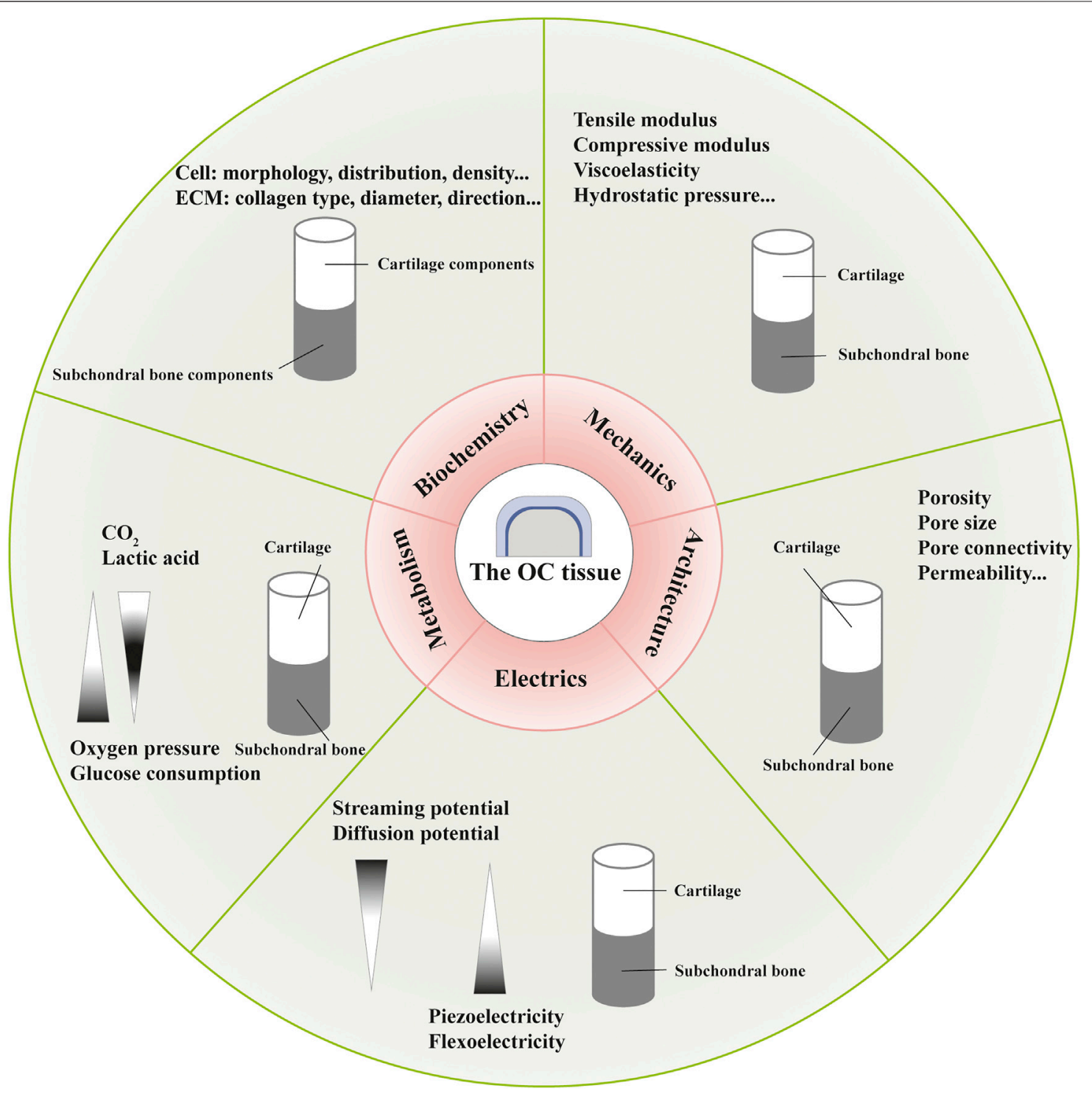

FIGURE 2 | Different gradients in the osteochondral (OC) tissue with regard to biochemistry, mechanics, architecture, electrics and metabolism.

architecture, electrics and metabolism, have been found in the OC tissue, which are not completely independent and act as the foundation for $\mathrm{OC}$ functional tissue engineering (Ansari et al., 2019; Li et al., 2021) (Figure 2).

The OC tissue exhibits cellular and compositional transitions from articular cartilage layer to subchondral bone layer (Figure 1). Within the articular cartilage layer, gradients of cell morphology, distribution and surrounding ECM can be observed (Ren et al., 2016). In the superficial/tangential zone, the flattened chondrocytes with the maximum cell density and highly packed collagen fibers aligned parallel to the articular surface, endowing the cartilage with tensile properties. As an anatomic and functional bridge between the superficial and radial zones, the transitional/middle zone contains more rounded cells at low density and thicker collagen fibers which are organized obliquely, functioning as the first line of resistance to compressive forces. Chondrocytes in the radial/deep zone are ellipsoid or rounded, arranged in columns perpendicular to the joint surface. Also, collagen fibers in this zone are organized vertical to the surface. In the CC layer, we can see sparce chondrocytes with hypertrophic types which can produce collagen X. The underlying bone tissue comprises a variety of cells such as osteoblasts, osteoclasts, osteocytes, chondrocytes, endothelial cells and mesenchymal stem cells (MSCs) (Florencio-Silva et al., 2015). Moreover, hydroxyapatite increases gradually moving from articular cartilage to bone layer. The specific composition and content of different gradients should be considered when designing complicated layered constructs in $\mathrm{OC}$ tissue engineering. For instance, polymers with various water absorption capabilities can be used in combination to mimic moisture gradient. Different growth factors can be integrated to rehabilitate specific differentiation paths. 
Essential constituents (collagen and proteoglycan, for instance) and mineralization degree lead to depth-dependent variations in mechanical properties including tensile modulus, compressive modulus, viscoelastic properties, and hydrostatic pressure (Responte et al., 2007; Chen et al., 2013; Armiento et al., 2018). Owing to the intrinsic material features of soft collagen fibers and rigid apatite crystals, and hierarchical arrangements more importantly, the bone layer develops diverse mechanical properties with regard to the loading direction as an anisotropic and viscoelastic material (Morgan et al., 2018). Accordingly, a collagen-apatite composite scaffold has been fabricated to restore bone-like hierarchical organization (Wingender et al., 2018). To repair OC tissue, metal alloys and ceramics have been used to mimic the strength and stiffness of subchondral layer, while polymers for the viscoelasticity of cartilage layer (Khorshidi and Karkhaneh, 2018). Fabrication techniques, such as electrospinning, can modify the mechanical properties of regenerated constructs by producing fibers with different diameters, components and structures. And bio-reactors can provided mechanical stimulation to mimic physiological conditions of OC tissue and control cell differentiation (Karkhaneh et al., 2014).

Architectural gradients refer to structural features such as porosity, pore size, pore connectivity and permeability. Articular cartilage has open and connected pores with a porosity of $60-85 \%$, while the cortical bone and trabecular bone are 5-30\% and 30-90\% porous, respectively, (Mow et al., 1992; Di Luca et al., 2015). With permeability changing in a deformation, direction and location dependent manner, the articular cartilage inhibits fluid loss and promotes nutrition transmission (Maleki et al., 2020). And the permeability of bone tissue changes with the density of osteocytes and fabric parameters (Kreipke and Niebur, 2017). These architectural properties are closely related to cell migration and vascular in-growth in tissue regeneration.

At present, three theories exist about the electrical characteristics of the cartilage layer: streaming potential, diffusion potential and piezoelectricity (Schmidt-Rohlfing et al., 2002; More and Kapusetti, 2017; Farooqi et al., 2019). The bone tissue can also generate electricity under pressure possibly due to piezoelectricity of collagen and flexoelectricity of bone mineral (Vasquez-Sancho et al., 2018). Scaffolds produced by piezoelectric materials can provide electrical energy and trigger signaling pathways associated with cell morphology maintenance, gene expression and biological functions, associated with tissue repair (Jacob et al., 2018).

In terms of metabolism, different properties of tissues result from mediums of physical transport-synovial fluid and blood vessels, respectively. The metabolic gradients include oxygen pressure, glucose consumption and waste products, which are associated with chondrocyte phenotype, cellular functions and environmental homeostasis (Sheehy et al., 2012; Karner and Long, 2018; Sieber et al., 2020; Suzuki et al., 2020). Controlled oxygen releasing biomaterials, such as hyperoxide and fluorinated compounds, are potential candidate for oxygen gradient formation in OC tissue engineering (Camci-Unal et al., 2013). And well designed bio-reactors can provide nutrients and remove waste products (Hossain et al., 2014).
Undoubtedly, to design a suitable construct for the rehabilitation of detected $\mathrm{OC}$ tissue is based on comprehensive understanding of native structure and physiology. Necessarily, multi-layered scaffolds, which are synthesized respectively and assembled subsequently, can not form a smooth transition between different layers, probably resulting in unsatisfactory simulation of native tissue interface. Several methods, such as microfluidic system, centrifugation, core-shell and layer-by-layer deposition, have been used to mimic physical and chemical gradients of native osteochondral tissue (Cross et al., 2016; Ansari et al., 2019). Advances in bio-reactors and fabrication techniques pave the way for mimicking the complex microenvironment of OC tissue. And coinduction of mechanical and electrical gradients combined with stratified metabolic regulation of cells should be concerned in future studies.

\section{CELL SOURCES IN OSTEOCHONDRAL TISSUE ENGINEERING}

In some OC tissue engineering strategies, scaffolds are preliminarily loaded with different cells to collectively promote tissue repair. Ideal cells for tissue engineering should have adequate sources and be able to maintain in vitro for manipulation and implantation safely. As shown in Table 1, two commonly proposed cell types for osteochondral repair are tissue-specific cells and progenitor cells, namely stem cells from different sources (Figure 3). Consistent with the host tissue, we usually use chondrocytes for hyaline cartilage repair and osteoblasts for subchondral bone regeneration. However, the use of differentiated cells suffers several limitations in the successive process of harvest, isolation, expansion, seeding, culture and finally implantation. For instance, chondrocytes are characterized by limited quantity in the native cartilage tissue, isolation difficulty and dedifferentiation capacity (Nukavarapu and Dorcemus, 2013). Since chondrocytes and osteoblasts both originate from bone marrow stem cells, MSCs have received widespread attention for their prominent advantages such as rapid proliferation and multipotency (Kagami et al., 2011; Mahmoudifar and Doran, 2013). Also, the secretory and immunomodulatory functions are closely related with cartilage regeneration. Various methods have been proposed for spatial and temporal control of differentiation toward the osteogenic and chondrogenic lineage including matrix properties and external factors, remaining to further explore and perfect (Seong et al., 2010; Mendes et al., 2018). Additionally, cell-free strategies have been pursued to overcome the aforementioned limitations (Maia et al., 2018). In combination with microfracture technology, biocompatible and biodegradable scaffolds without cells are implanted to promote cell recruitment and differentiation within the osteochondral defect area. Moreover, alternative approaches participated by MSC-derived exosomes or extracellular microvesicles have been developed in tissue repair and regeneration (Kim et al., 2020). 
TABLE 1 | Cell resources in osteochondral tissue engineering.

\begin{tabular}{|c|c|c|}
\hline Cell types & Cell sources & Relevant characteristics \\
\hline \multirow{5}{*}{ Tissue-specific cells } & & Limited quantity in the native tissue \\
\hline & & High integration into the surrounding matrix \\
\hline & Osteoblasts & The expression of Runx2 peaks in immature osteoblasts and reduces at maturity Komori, (2019) \\
\hline & & Enhanced apoptosis by p53 and accelerated differentiation through Akt-FoxOs pathway Komori, (2016) \\
\hline & & Osteoblast-derived VEGF promotes bone repair and homeostasis Hu and Olsen, (2016) \\
\hline \multirow{11}{*}{ Progenitor cells } & & Immunomodulatory functions, facilitating better tissue survival in vivo Sun et al. (2018); Ding et al. (2016) \\
\hline & UC-MSCs & Inexhaustible supply, noninvasive procurement and high purity \\
\hline & & Faster proliferation rates, greater expansion capability and broad multipotency Baksh et al. (2007); Chen et al. (2009) \\
\hline & & More primitive-expressing both MSC and ESC markers Barrett et al. (2019) \\
\hline & & No or only mild immune response based on recent evidence Prasanna et al. (2010); Liu et al. (2012) \\
\hline & AT-MSCs & Increased osteogenic differentiation by allylamine modification Murata et al. (2020); Chaves et al. (2016) \\
\hline & AFSCs & $\begin{array}{l}\text { Expressing Runx2, osterix, osteopontin et al. and producing extracellular calcium stores during differentiation Maraldi et al. } \\
\text { (2011) }\end{array}$ \\
\hline & & $\begin{array}{l}\text { Typical differentiation process into cells of mesodermal origin regulated by growth factors (e.g., TGF- } \beta \text {, IGF- } 1 \text { and EGF) } \\
\text { Bajek et al. (2014) }\end{array}$ \\
\hline & uscs & A recently reported candidate for seed cells in tissue engineering Gao et al. (2016) \\
\hline & & Osteogenic and chondrogenic potentials worth exploring Qin et al. (2014) \\
\hline & & $\begin{array}{l}\text { Simple isolation and culture, non-invasive and easy obtainment, low-cost and high efficiency Zhang et al. (2008); Guan et al. } \\
\text { (2014) }\end{array}$ \\
\hline
\end{tabular}

Abbreviations: BM-MSCs, Bone marrow-derived MSCs; UC-MSCs, Umbilical cord MSCs; AT-MSCs, Adipose tissue-derived MSCs; SDSCs, Synovium-derived MSCs; AFSCs, Amniotic fluid-derived stem cells; USCs, Urine-derived stem cells.

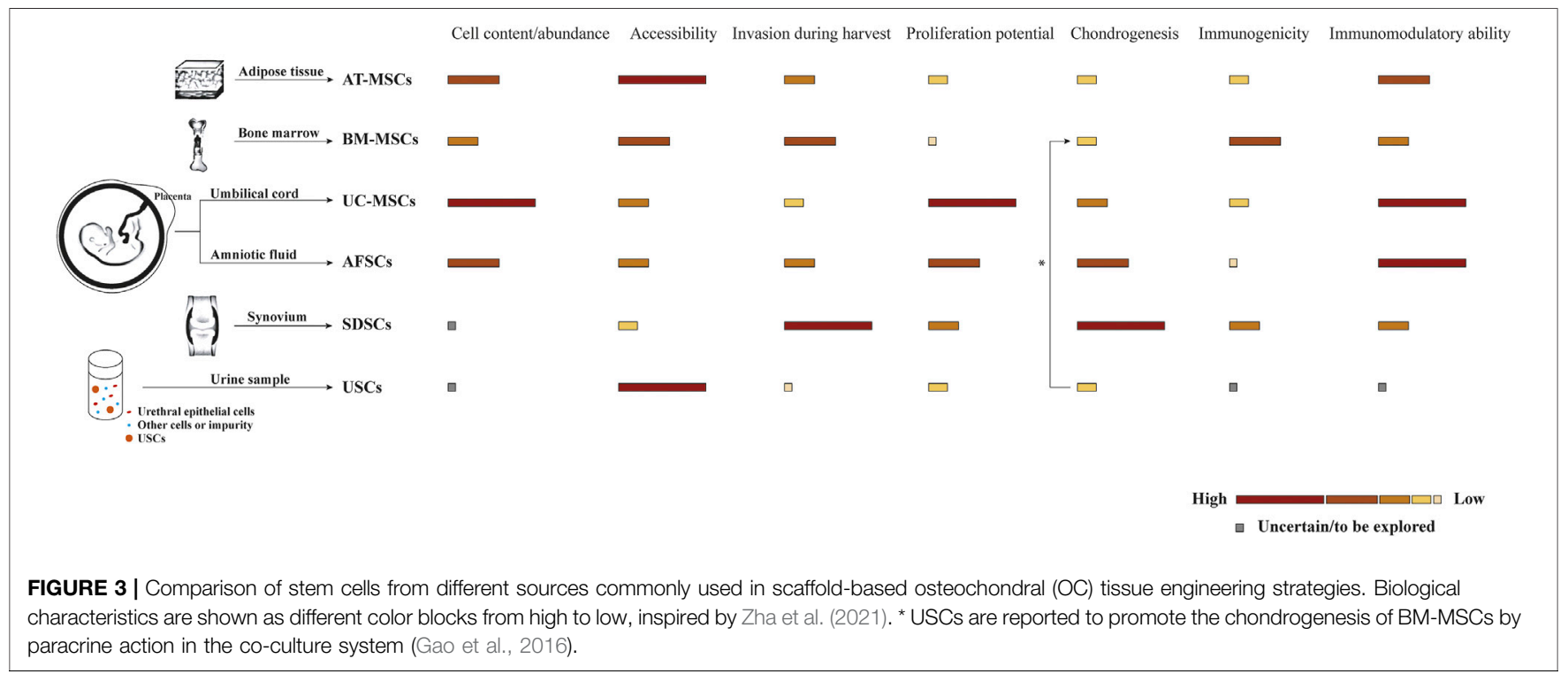

\section{SCAFFOLD FABRICATION TECHNIQUES}

Scaffolds are one of the fundamental elements of tissue engineering approaches to osteochondral repair. For the quality of tissue regeneration, scaffolds are expected to have the following characteristics: porous structure for cell survival and material transport, suitable surface for cell adhesion, proliferation and differentiation, mechanical properties matching the surrounding tissue, biocompatibility with limited immunoreaction and 
TABLE 2 | Fabrication techniques of scaffolds in osteochondral tissue engineering.

Techniques

Processes

\section{The pros and cons}

Lyophilization

Freeze casting

Gas foaming

Microfluidic foaming

Sol-gel process

Solvent casting

Melt molding

Compression molding

Particulate leaching

Phase separation process

Electrospinning Electrospinning
The mixture is cooled by freeze-drying to eliminate the solvent and water, forming macropores and micropores in the scaffold structure
The manufacturing technique includes the controlled solidification process, the sublimation of solvents under reduced pressure and subsequent densification

The raw materials are kept under a high carbon dioxide pressure to produce porous structures

The foam is generated via microfluidics under highly controlled and reproducible conditions

The sol-gel method can result in oxides or hybrid materials in soft conditions

The polymer solution is first combined with necessary particles and then poured onto pre-designed molds

The mixture of powdered polymers and porogen is loaded into predesigned molds and annealed at an elevated pressure

The mixture is pressed into molds under heat and pressure to obtain the required structures. Sempertegui et al. (2018); Zhang et al. (2016)

The preliminarily obtained scaffolds are treated and soaked to leach out particles

The polymer solution is quenched under the freezing point (Tk) and separated into a polymer-rich phase and a polymer-poor phase which will solidify and crystallize respectively. Crystals are removed subsequently

Under a strong electric field, a polymer solution, emulsion or melt is extruded through a spinneret to produce fibre and deposit on an appropriate collector
Additive manufacturing (AM)
The electrohydrodynamic technique, also known as rapid prototyping or solid freeform fabrication, is classified into seven processes: vat photopolymerization, material jetting, material extrusion, powder bed fusion, directed energy deposition, sheet lamination and binder jetting. Tang et al. (2016); Gibbs et al. (2014)
- The pore size and porosity can be modified by solution characteristics (e.g., concentration and viscosity), quenching rate and freezing temperature (Tf). Raeisdasteh Hokmabad et al. (2017)

- The use of organic solvents; instability of the emulsion

- The applicability to various materials; changeable micro- and macrostructures of obtained scaffolds

- The uniformity of cell infiltration should be improved. Salonius et al. (2019)

- Homogeneous pore monodispersity and interconnection; abundant cell infiltration; versatility. Costantini et al. (2016)

- There is still room to expand the range of applicable biomaterials

- Combined with other techniques, such as 3D printing, this approach can open a new way for the design of biocompatible hydrogels by promoting cross-linking. Valot et al. (2019); Tourné-Péteilh et al. (2019); Raucci et al. (2018)

- Addition of functional elements such as drugs and growth factors

- The potential toxicity of organic solvents

- Porous scaffolds with desired morphological features

- The difficulty of later particulate leaching; high processing temperature; inapplicability of organic solvents

- High-pressure molding can compact the stacking structure and optimize mechanical performance

- Porous structures adjusted by the added porogen as required

- The technical demands for better control of pore morphology and interconnection; extra time consumption

- The scaffold structure can be tunable on account of processing parameters such as quenching temperature and rate

- The improvement and integration of techniques is needed to optimize the probably unfavorable pore structure

- Structures resembling the native ECM; encapsulation of bioactive elements

- Poor control over architectures restricted by environmental parameters; difficulty in producing 3D structures; limited cell passage and substance exchange related to pore size; environmental safety issues

- Better control over architectures; flexibility to scale-up customisation; standardisation and repeatability of manufacturing

- Narrow range of suitable materials, time-consuming layer-by-layer processing and high costs bioabsorbability with a controllable degradation rate (Hutmacher, 2000).

To improve scalability, sustainability and spatial control, various methods for scaffold fabrication in osteochondral tissue engineering have been proposed, including lyophilization, freeze casting, gas foaming, sol-gel process, solvent casting, compression molding, particulate leaching and phase separation process et al. (Hutmacher, 2000; Cheng et al., 2019) (Table 2). Seo JP et al. utilized the freeze-drying technology to prepare bilayer gelatin/ $\beta$-tricalcium phosphate (GT) sponges (Seo et al., 2013). In their study, PRP/BMP-2/GT scaffolds showed more cartilage-like tissue with no remaining implant materials and no evidence of infection, adhesions or synoyial proliferation. To establish various bioactive scaffolds, the use of freeze casting has drawn much concern in recent years. In a previous study, Abarrategi A et al. performed both in vitro and in vivo assays of cell survival and bone formation based on rhBMP2/multiwall carbon nanotubes (MWCNT)/chitosan (CHI) scaffolds in conjunction with freeze casting (Abarrategi et al., 2008). The technology has high application value and development potential in forming structures in accordance with natural tissue (Shao et al., 2020). Reyes R et al. analyzed the effects of repair induced by TGF- $\beta 1 / \mathrm{BMP}-2$ loaded segmented polyurethane/polylactic-co-glycolic (SPU/PLGA) scaffolds in osteochondral lesions (Reyes et al., 2014). The PLGA porous structure was produced by gas foaming in acidic aqueous solution. Algul D et al. manufactured multilayered $\beta$ $\mathrm{TCP} /$ chitosan-alginate polyelectrolyte complex (CA/PEC) scaffolds to mimic the structural gradients of native osteochondral tissue (Algul et al., 2015). The chitosan and alginate solutions were mixed and stirred to prepare a gel. The chitosan/alginate gel was treated through a series of steps for scaffold fabrication such as lyophilization, cross-linking and elution. $\mathrm{Wu}$ et al. evaluated the efficacy of bilayered silk scaffolds loaded with TGF- $\beta 3 /$ BMP-2 for osteochondral defect repair in rabbits aided by the solvent casting/particulate leaching 

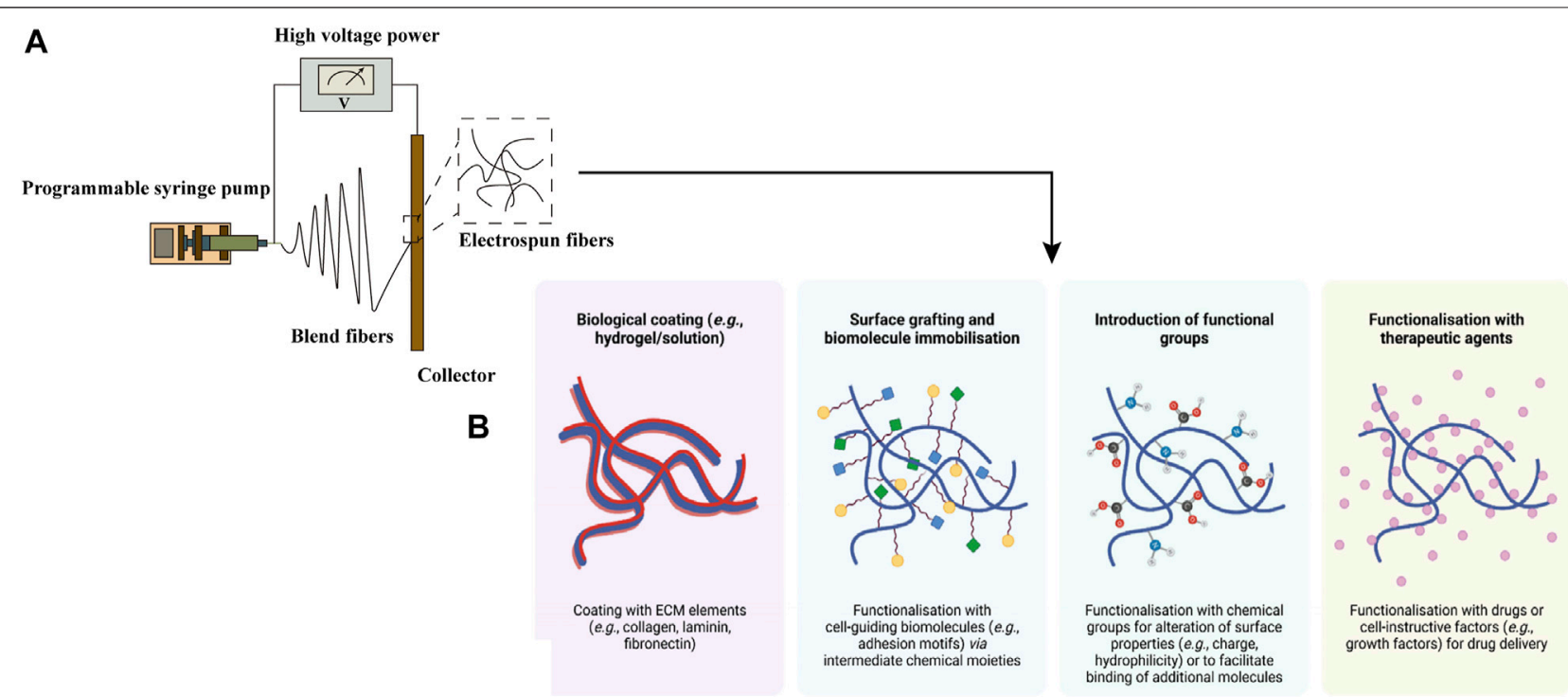

FIGURE 4 | Electrospun fibers, obtained by basic electrospinning setup (A), can be modified by physical or chemical techniques. Post-fabrication surface modifications of electrospun fibers (B) were adapted with permission from ref (Gonçalves et al., 2021). Copyright 2021 by MDPI Inc.

technology (Wu et al., 2021). The lyophilized silk powder was first mixed with hexafluoroisopropanol (HFIP) solution with or without sucrose particles in a silicone mold. Then, $10 \%$ silkHFIP solution was poured onto the mold and kept for crosslink. The demolded scaffolds were treated with methanol $(100 \% \mathrm{w} / \mathrm{v})$ and running water to remove the HFIP and particles. After the process above, the top and bottom layers of scaffolds served as the cartilage and subchondral bone layers, respectively. Moreover, Sil-MA (methacrylated silk fibroin) hydrogels for marginal sealing were prepared by photo curing. This new approach indicated the effect of the marginal sealant on the integration of the cartilage layer and rapid cartilage formation. Duan et al. investigated the effects of pore size on osteochondral repair in vivo using a rabbit model (Duan et al., 2014). The bilayered poly(lactide-co-glycolide) (PLGA) porous scaffolds for research were fabricated by a compression molding/particulate leaching method. The PLGA solution and sodium chloride $(\mathrm{NaCl})$ particulates as porogen were mixed and pressed into the predesigned mold. After releasing the mold, cylindrical structure was obtained. Then, the mixture constructs were cut into appropriate sizes and leached by water. Five types of integrated scaffolds with identical porosity and different pore sizes were processed finally. The assessment in this study reminded us to take pore sizes into consideration during scaffold design for tissue engineering. Da et al. prepared the compact layer between the chondral and bony layers from PLGA/ $\beta$-TCP by the phase separation process ( $\mathrm{Da}$ et al., 2013). The homogeneous PLGA/ $\beta$-TCP mixture was compactly extruded and solidified line by line above the subchondral bone layer. Through in vitro and in vivo tests, the compact layer-containing biphasic scaffolds showed better biomechanical properties and tissue repair results.

With the development of manufacturing, an advanced technique named electrospinning has been applied to produce functional scaffolds with spatially complex physical and chemical properties in osteochondral tissue engineering (Figure 4). To reduce the inflammatory immune responses, natural polymers such as collagen and silk fibroin have been employed as scaffold materials. Liu et al. fabricated a nanofiber yarn-collagen type I/hyaluronate hybrid (Yarn-CH)/TCP biphasic scaffold by dynamic liquid electrospinning, which showed an almost smooth articulating surface and good integrity of the hostimplant interface (Liu S et al., 2015). Composite electrospun matrix derived from $70 \mathrm{~S}$ bioactive glass and silk fibroin was obtained and evaluated as potential candidate for osteochondral defect repair by $\mathrm{M}$ JC et al. (M et al., 2017). The biphasic constructs showed the ability to synergistically support the chondrogenic and osteogenic growth. Also, certain synthetic polymers have been used as bioassimilable materials, including PCL, PLA and PLGA in particular (Liu W et al., 2015). The nanofibers fabricated by electrospinning technique can present a high surface area for cell growth and cellular differentiation (Aguirre-Chagala et al., 2017). Continuously graded insulin/ $\mathrm{PCL} / \beta$-GP scaffolds, fabricated via the application of the twinscrew extrusion/electrospinning method, have implemented the selective differentiation of h-ADSCs into chondrocytes and mineralized tissue hierarchically (Erisken et al., 2011). In the study of Baumgartner W et al., electrospun meshes of PLGA/ amorphous calcium phosphate (aCaP) seeded with h-ADSCs were cultured in DMEM to explore the effects of $\mathrm{aCaP}$ and shear forces on osteogenic, chondrogenic, adipogenic and angiogenic stimulation (Baumgartner et al., 2019). To improve the reparative potential of irregular osteochondral defects, the cell/nanofibers composite electrospun scaffolds with a slurry-like texture have been produced. Kim HS et al. prepared the cartilagedECM-decorated PCL electrospun scaffolds which were surfacemodified with poly(glycidyl methacrylate) (PGMA@NF) via surface-initiated atom transfer radical polymerization (SIATRP) method (Kim et al., 2021). The in vivo study in a rat 
model indicated significantly improved cartilage and bone regeneration of osteochondral defects. To provide molecular cues and improve the spatiotemporal control of cell distribution and differentiation, Liu YY et al. reported a functional gradient scaffold consisting of gelatin/sodium alginate (SA) struts and electrospun nanofibers incorporated by gentamycin sulfate (GS) and desferoxamine (DFO) (Liu et al., 2016). Fabricated via a system which combined 3D biological printing and electrospinning process, the scaffold showed excellent mechanical stability. Loaded with different biomolecules, the 3D composite osteochondral scaffolds can achieve spatiotemporal release according to various requirements.

Osteochondral scaffold manufacturing that can produce tunable structure in terms of architectural, biomechanical and biochemical properties is an ideal candidate for tissue engineering. Additive manufacturing (AM), an electrohydrodynamic technique, is gradually coming into focus. Characterized by layered sedimentation and computeraided design/manufacturing (CAD/CAM) technology, AM methods include fused deposition modeling (FDM), selective laser sintering (SLS) and inkjet 3D printing et al. (Gonçalves et al., 2021). Ding C et al. designed a CAD/CAM-fabricated scaffold from polylactic acid-coated polyglycolic acid (PGA/PLA) and poly- $\varepsilon$-caprolactone/hydroxyapatite (PCL/HA) for goat femoral head regeneration (Ding et al., 2013). The PGA/PLA and PCL/HA scaffolds were respectively fabricated by $3 \mathrm{D}$ printing and FDM with aid of CAD/CAM technology. The strategy in this study provided a promising approach for tissue specific regeneration with cartilage tissue, immature calcified tissue, transitional trabecular bone and hypertrophic chondrocytes. Significantly, these methods can integrate bioactive molecules or drugs into scaffolds derived from various biomaterials. Tamjid E et al. prepared PCL composite scaffolds containing tetracycline hydrochloride $(\mathrm{TCH})$ by $3 \mathrm{D}$ printing and tested the performance of biocompatibility, drug release kinetics and antibacterial activity (Tamjid et al., 2020). This study has paved the way for realizing sustainable release of loaded medicine. In another instance, an air-extrusion 3D printing technique was utilized to fabricate a scaffold consisting of poly(N-acryloyl 2-glycine)-methacrylated gelatin (PACG-GelMA)- $\mathrm{Mn}^{2+}$ for cartilage layer and PACG-GelMAbioactive glass (BG) for bone layer (Gao et al., 2019). In vitro experiments indicated increased gene expression of both chondrogenic- and osteogenic-related differentiation. Also, the biohybrid scaffold promoted osteochondral tissue regeneration after implantation in a rat model. With excellent elasticity, hybrid scaffolds can support various deformation. In some cases, osteochondral defects are closely associated with mitochondrial dysfunction, metabolic reconfiguration and increased heterochromatin, which provides a potential avenue to design functional scaffolds for tissue regeneration (Varela-Eirin et al., 2018; Coryell et al., 2021). Chen P et al. examined the therapeutic potential of MSC-derived exosomes in 3D printed ECM/GelMA scaffolds (Chen et al., 2019). In vitro studies demonstrated increased chondrocyte migration by the scaffolds, which has been reported as a major element in the repair process of osteochondral defects (Chen et al., 2015; Zhang et al., 2018). The healing capacity was then assessed in a rabbit model. After implantation, the ECM/GelMA/exosome scaffold was shown to restore the damaged chondrocyte mitochondria by providing critical proteins and stimulate M2 macrophage polarization in the synovium. Advances in manufacturing have allowed the development of in situ 3D printing technology for osteochondral tissue repair, thereby improving the surgical procedure and the graft accuracy (Ma et al., 2020). However, mass industrial implementation and clinical applications are limited by several limitations: narrow range of suitable materials, time-consuming layer-by-layer processing and high costs, et al. Further exploration is needed to accelerate the clinical translation and fill the gap in osteochondral defect treatment.

\section{DIFFERENT TYPES OF SCAFFOLDS IN OSTEOCHONDRAL TISSUE ENGINEERING}

As a vital component of tissue engineering and regenerative medicine, scaffolds play an increasingly important role in the reconstruction and maintenance of tissue functions. Under the regulation of essential parameters, such as growth factors and functional particles, they can provide a platform for cell survival, proliferation and differentiation, thereby raising the possibility of tissue repair. Today, advances in biomaterials and fabrication techniques provide new opportunities for the development of biomimetic and sophisticated scaffolds, which can be further divided into monophasic, biphasic and multiphasic constructs. Apparently, multiphasic scaffolds have several advantages in bionic performance over the monophasic ones. In the following sections, we focus on different types of biphasic and multiphasic scaffolds for OC tissue engineering on the basis of biomaterial design (Supplementary Table S1).

\section{Porous Scaffolds}

There are various forms of porous scaffolds, including foam, sponge, mesh, microfibers and nanofibers, etc. The porous structure can function as an important support for cell aggregation and infiltration to guide further differentiation towards diverse lineages. Moreover, the interconnected pore networks with appropriate pore size and porosity are the forming basis of extracellular matrix simulating the native $\mathrm{OC}$ tissue. The resulting microenvironment can promote nutrient supply and stimulate effective cell-cell and cell-matrix communications. More significantly, the macro- and micropores of scaffolds are crucial channels for blood vessel and nerve growth. Considerable efforts have been made to optimize the structures of porous scaffolds to serve specific functions through tissue regeneration. As mentioned in the previous section, Duan P et al. first assessed the effects of pore size on the efficacy of in vivo osteochondral tissue repair (Figures $\mathbf{5 A}, \mathbf{B})$. Until now, researchers have not yet reached a consensus on the ideal pore morphology. In addition to pore size and porosity, more descriptive parameters (e.g., tortuosity and surface area to volume ratio, et al.) have been supplemented to characterize and evaluate scaffolds. 

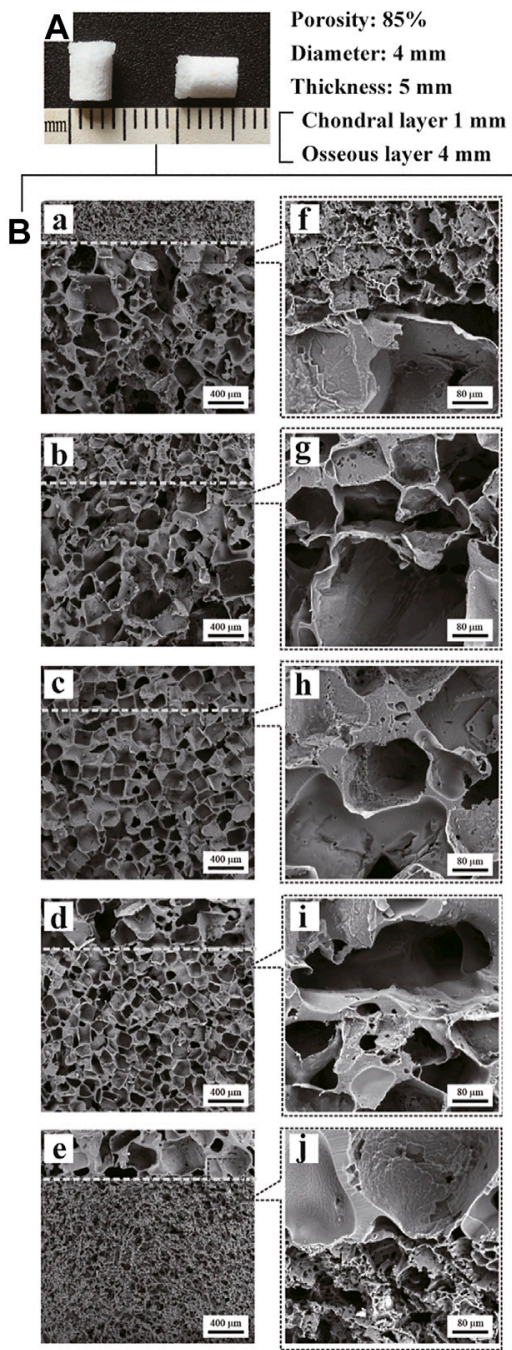
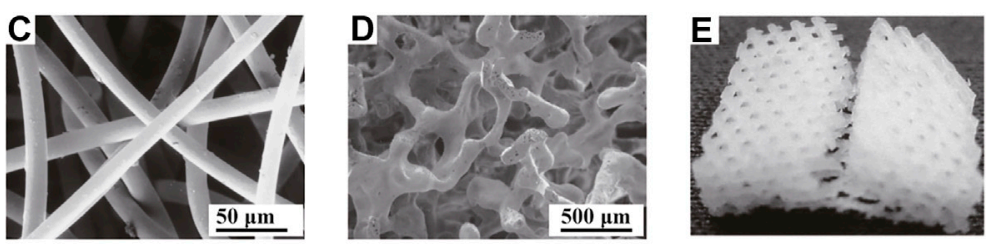

$\mathbf{F}$
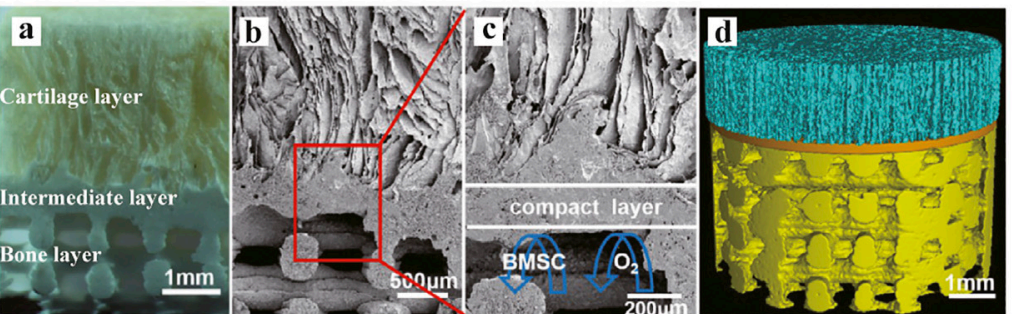

$\mathbf{G}$
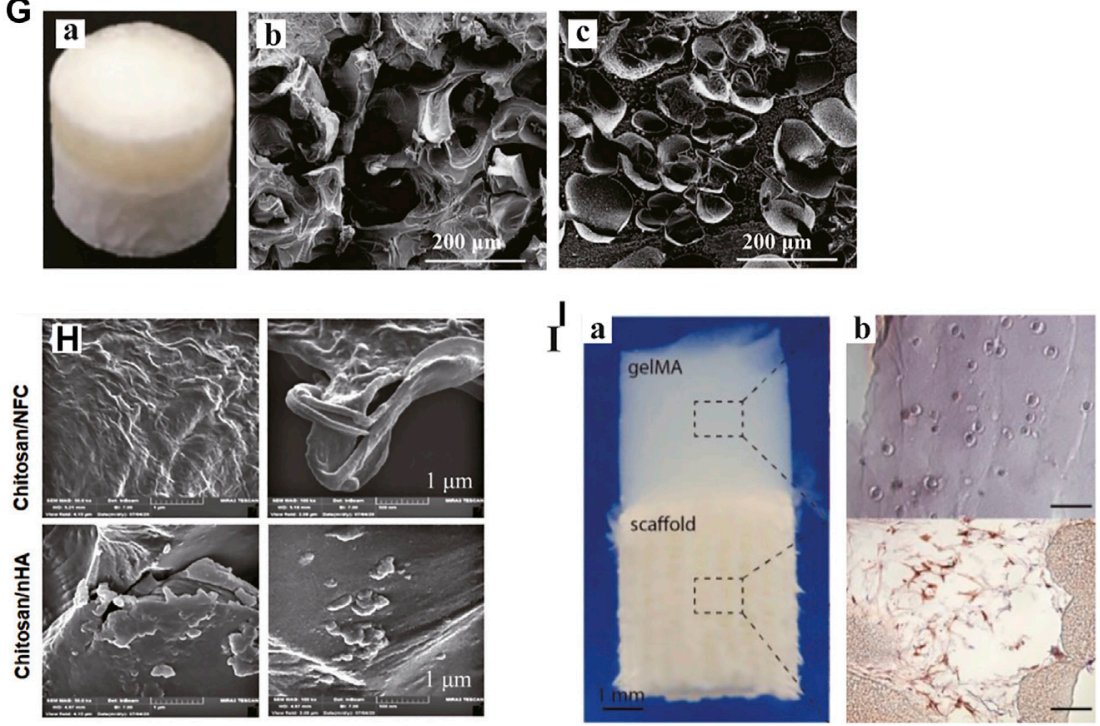

FIGURE 5 | Porous and hydrogel scaffolds. Bilayered PLGA porous scaffolds (A) with different pore sizes shown in scanning electron microscopy (SEM) images (B: a-e). The boundaries between the layers were magnified (B: $\mathbf{f - j}$ ). Bilayered porous scaffold consisting of non-woven PGA meshes (C) and PLGA/PEG foams (D). PCL porous scaffold with a 0/60/120 lay-down pattern (E). Muti-layered scaffolds with porous 3D printing PLGATCP bone layer (F) were shown in digital pictures (F: a), SEM images (F: b-c) and micro-CT reconstructive images (F: d), respectively. Bilayered CAN-PAC hydrogel (G: a) and the SEM images of upper (G: b) and lower layers (G: c). SEM images of the upper and lower layers of chitosan hydrogel scaffold (H). Tri-phasic scaffolds made of gelMA hydrogel and PCL/HA (I: a). CD31 immunohistochemical analysis showed the presence of HUVECs in the PCL-PCL/HA phase (I: b). (A, B) Adapted with permission from ref (Duan et al., 2014). Copyright 2013 by WILEY PERIODICALS Inc. (C, D) Adapted with permission from ref (Schaefer et al., 2000). Copyright 2000 by Elsevier Science Ltd. (E) Adapted with permission from ref (Cao et al., 2003). Copyright 2003 by Mary Ann Liebert Inc. (F) Adapted with permission from ref (Jia et al., 2018). Copyright 2018 by American Chemical Society. (G) Adapted with permission from ref (Liao et al., 2017). Copyright 2017 by Nature Publishing Group. (H) Adapted with permission from ref (Dehghani Nazhvani et al. 2021). Copyright 2021 by Elsevier Inc. (I) Adapted with permission from ref (Pirosa et al., 2021). Copyright 2021 by Elsevier Ltd.

Ideal porous scaffolds for clinical applications in osteochondral tissue engineering should meet both structural and functional requirements. Different layers of the scaffolds can mimic the natural gradients of the OC tissue. After implantation, the scaffolds can stimulate tissue regeneration and integration with the surrounding cartilage and subchondral bone. Natural and synthetic polymers are commonly employed as biomaterials. In an earlier in vitro study, Schaefer D et al. dynamically seeded the fibrous, nonwoven PGA meshes and PLGA/PEG foams with chondrocytes and periosteal cells, respectively, (Figures 5C,D). Then, the two cell-polymer constructs were cultured independently and sutured together for an additional co-culture in osteogenic medium. Mature bone-like constructs in combination with immature cartilaginous constructs were suggested to promote integration at the tissue interface. Seo JP et al. inserted PRP/acidic GT sponges loaded with chondrocytes and BMSCs and BMP-2/ basic GT sponges loaded with BMSCs into the upper and lower part of osteochondral defects separately in a horse model (Seo et al., 2013). The GT sponges prepared have a porosity of $95.9 \%$ with the pore size of $179.1 \pm 27.8 \mu \mathrm{m}$. Sponges have better mechanical stability compared to meshes. 
To date, there have been various multi-layered porous scaffolds reported based on different fabricating techniques. Dresing I et al. demonstrated PUR and nHA/PUR scaffolds consisting of three regions (Dresing et al., 2014). The scaffolds were assembled via a solvent welding technique. Jia $\mathrm{S}$ et al. designed a biomimetic multi-layered scaffold (Figures 5F). The scaffold comprised three integrated layers: an oriented ACECM-derived cartilage layer, an intermediate compact interfacial layer and a 3DP porous PLGA/ TCP layer. The heterogeneous porous constructs provided a suitable template to guide hyaline cartilage, calcified cartilage and subchondral bone growth.

\section{Hydrogel Scaffolds}

The extracellular matrix of osteochondral tissue is gelatinous substance containing fibrous components (Khorshidi and Karkhaneh, 2018). Because of the structural and compositional resemblance to natural ECM, natural and synthetic hydrogel scaffolds have great potential in tissue regeneration due to their intrinsic properties, such as biocompatibility, biodegrability and cell interaction. Natural materials used in hydrogels, including decellularized ECM, collagen, chitosan and hyaluronic acid etc., possess satisfactory biocompatibility with no inflammation and cytotoxity, whereas synthetic polymers are easier to process and control (Naahidi et al., 2017). To balance the degradability of scaffolds and the adhesions of cells is the key to design hydrogels for tissue repair. Responsive hydrogel materials are considered as potential candidate for biological platforms due to their adaptive responses to physiological stimuli in the environment. And hydrogel-based soft-hard interfaces, which can regulate homeostasis in the interfacial microenvironment, deserve attention in future studies (Fang et al., 2021).

A biphasic CAN-PAC hydrogel was fabricated by Liao J et al. for osteochondral defect regeneration in a rabbit model (Figures 5G). CSMA and NIPAm were dissolved in the upper solution, meanwhile, PECDA, AAm and PEGDA were added in the lower solution. The hydrogel facilitated the formation of new translucent cartilage and repaired subchondral bone. Also, a hypoxic preconditioned chitosan-based hydrogel has shown a faster healing trend, with thicker cartilage and more new ECM formation (Figures 5H). More recently, Pirosa A et al. used solid gelMA hydrogel in combination with wet-spun PCL and PCL/ $\mathrm{HA}$ to generate an in vitro vascularized osteochondral tissue model (Figures 5I). In another study, an injectable and selfhardening hydrogel of silylated cellulose and chitosan showed the potential for osteochondral tissue repair in a dog model (Boyer et al., 2020).

\section{Fibrous Scaffolds}

Actually, fibrous scaffolds can be classified as porous microfiber or nanofiber scaffolds, which offer a microenvironment favorable for cell attachment and survival. Various materials and techniques can be utilized for fabrications. Electrospinning, in particular, is an widely used technique. Moreover, the fibers can be specifically functionalized by the controlled release of drugs and biomolecules. The application of fibrous scaffolds to osteochondral tissue engineering makes it possible to customize properties as required, including pore morphology, resilience, flexibility and bioactivity etc.

In osteochondral tissue engineering, materials used to produce fibrous scaffolds include natural polymers, synthetic polymers, cellulose fibers, mineral fibers and carbon fibers (Hild et al., 2011; Yunos et al., 2013; Baah-Dwomoh et al., 2015). Liu S et al. produced a nanofiber yarn-collagen type I/hyaluronate hybrid (Yarn-CH)/TCP biphasic scaffold for osteochondral defect repair in a rabbit model. The nanofibrous scaffold showed an almost smooth articulating surface and good integration of cartilageimplant interface. A bilayered microporous scaffold was fabricated with collagen and electrospun poly-L-lactic acid nanofibers (COL-nanofibers) by Zhang $S$ et al. The study reported more rapid osteogenic differentiation and better cartilage formation induced by the nanofibrous scaffold. Another nanofibrous scaffold, namely XanoMatrix, contains polyethylene terephthalate and cellulose acetate (Bhardwaj and Webster, 2016). With great hydrophobicity, 3D surface area and high tensile strength, the scaffold is a candidate for osteochondral defect treatment. Elangomannan $\mathrm{S}$ et al. evaluated the properties of carbon nanofibers/PCL/mineralized hydroxyapatite (CNF/ PCL/M-HAP) scaffolds and reported the potential for orthopedic applications (Elangomannan et al., 2017).

\section{Microsphere Scaffolds}

As an important candidate as building blocks of scaffolds, microspheres (MSs) show advantages in the following respects: biomimetic structural support, biological regulation, controlled release of biomolecules and drugs, cell delivery in vivo and large scale production ( $\mathrm{He}$ et al., 2020). According to the purpose, scaffolds loaded with MSs come in two types: MS-leached scaffolds and MS-incorporated scaffolds (Figure 6).

In the former type, MSs serve as porogens to produce homeostatic and regular porous structure. Several studies have reported better cell infiltration and tissue invasion based on MSleached scaffolds (Zaborowska et al., 2010; Huebsch et al., 2015). In the latter type, MSs are used to modify sophisticated biological functions, thereby showing promise for development of osteochondral tissue engineering. MSs based on hydroxyapatite, calcium carbonate, chitosan and PLGA etc. have been reported to use for scaffold fabrications to improve mechanical strength and bioactivity (Shalumon et al., 2016). Cellencapsulated MSs can protect the inner cells and allow bidirectional substance exchange (Bozkurt et al., 2019). Moreover, MSs loaded with drugs or biomolecules can exert therapeutic effect and regulate cell metabolism (Dormer et al., 2010). Reyes $\mathrm{R}$ et al. incorporated MSs loaded with TGF- $\beta 1$ and BMP-2 into a bilayered scaffold to induce chondrogenic and osteogenic differentiation, separately (Reyes et al., 2014). The microsphere scaffold was reported to induce a high degree of tissue repair based on histological evidence. In addition, one study encapsulated $45 \mathrm{~S} 5$ bioactive glass particles (BG) in PLGA MSs, which facilitated mineral formation in the interface and bone regions (Jiang et al., 2010). Mohan N et al. fabricated PLGACS-NaHCO 3 as chondrogenic MSs and PLGA- $\beta$-TCP as osteogenic MSs to produce a gradient scaffold (Mohan et al., 2015). Recently, various studies have reported the utility of drug 

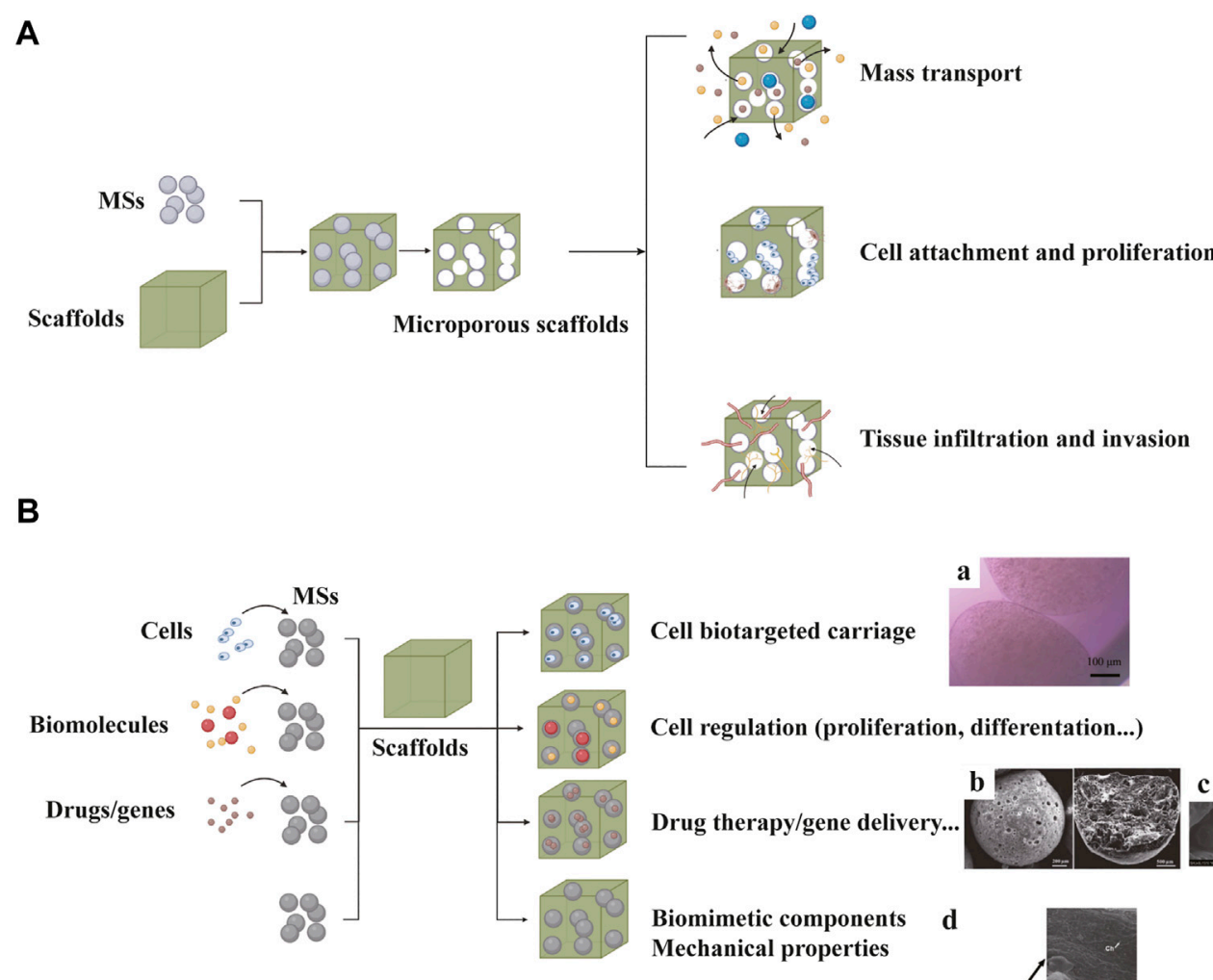

Cell biotargeted carriage

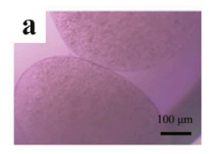

Cell regulation (proliferation, differentation...)

Drug therapy/gene delivery...

Biomimetic components d Mechanical properties

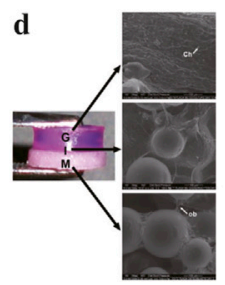

FIGURE 6 | Microsphere (MS) scaffolds can be classified into MS-leached scaffolds (A) and MS-incorporated scaffolds (B). Chondrocyte-encapsulated MSs can provide protection and achieve targeted carriage (B: a). MS scaffolds loaded with vancomycin hydrochloride (VH) can reduce inflammation after implantation (B: b). MS scaffolds loaded with OIC-A006 (B: c). Multi-layered scaffold consisting of pre-integrated hydrogel (G), hydrogel + microsphere interface (I) and microsphere (M) bone layers (B: d). (B-a) Adapted with permission from ref (Bozkurt et al., 2019). Copyright 2019 by BioMed Central Ltd. (B-b) Adapted with permission from ref (He et al., 2021). Copyright 2020 by Elsevier Ltd. (B-c) Adapted with permission from ref (Lin et al., 2016). Copyright 2016 by Taylor and Francis Group. (B-d) Adapted with permission from ref (Jiang et al., 2010). Copyright 2010 by Biomedical Engineering Society.

or gene delivery MSs for effective osteochondral tissue regeneration (Lin et al., 2016; Madry et al., 2020; He et al., 2021).

\section{Metal Scaffolds}

To date, limited studies on metal scaffolds have been reported. Mrosek EH et al. used trabecular metal/periosteal graft (TMPG) biocomposites to treat osteochondral defects in a sheep model (Mrosek et al., 2016). The metal scaffolds showed excellent bony ingrowth and integration, but failed to promote satisfactory neocartilage formation, unfortunately. Another metal worth mentioning is titanium (Ti), a highly corrosion resistant and biocompatible material with superior mechanical properties (Nover et al., 2015). Given the ability to promote cartilage growth and allow bone tissue ingrowth, porous titanium has been proposed as a viable bone-like base material for osteochondral tissue engineering. The mechanical support of subchondral bone has been reported as an essential part in articular cartilage protection ( $\mathrm{Hu}$ et al., 2021). Therefore, metallic materials have been employed in OC tissue repair as subchondral bone phase. Duan X et al. fabricated a biphasic scaffold composed of type I collagen (Col)/glycosaminoglycan (GAGs) as chondral phase and porous titanium as subchondral phase (Duan et al., 2013). Sing SL et al. combined the two metals mentioned above to develop a biphasic metal scaffold for osteochondral defect repair (Sing et al., 2017). The titaniumtantalum (TiTa)/type I collagen scaffold demonstrated continuous interface between the two phases, the biological functions of which need to be further evaluated. The poor biodegradability and unsatisfactory performance in mimicking articular cartilage tissue have been the major obstacles to widespread application of metals (Díaz Lantada et al., 2016).

\section{Composite Scaffolds}

The use of composite scaffolds in tissue engineering can integrate the advantages of polymers and ceramics. Various bioceramics have been used for scaffold fabrication, mainly summarized into 


\section{A} 4\% Cartilage Layer $4 \%$ chitosan $+1 \%$ hyaluronic acid

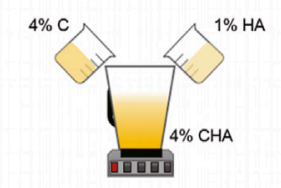

Homogenize

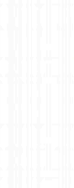

$\underbrace{2}$
$6 \%$ chitosan $+6 \% \frac{\text { Bone Layer }}{\text { alginate }+0.5 \% \text { hydroxyapatite }}$

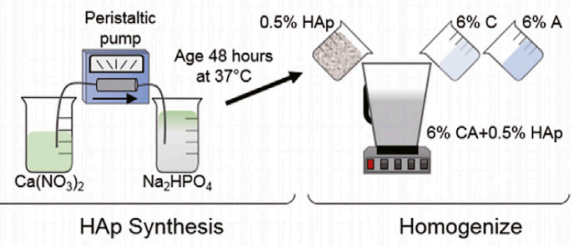

Layer, centrifuge, freeze, and lyophilize to fabricate bilayer scaffolds.
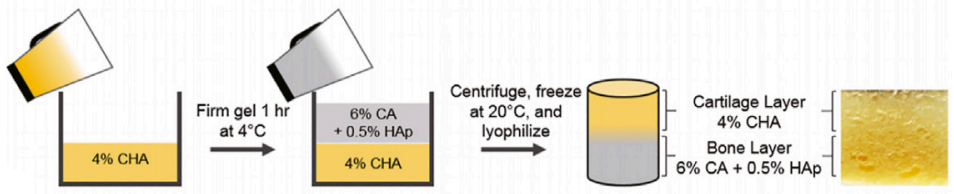

B
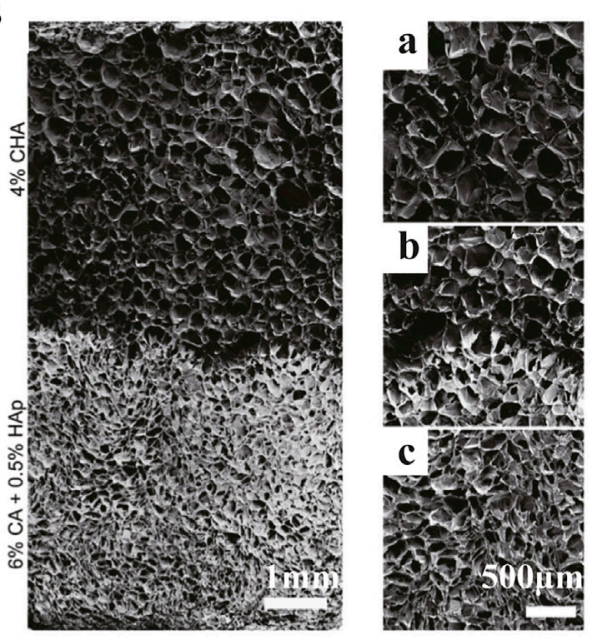

C
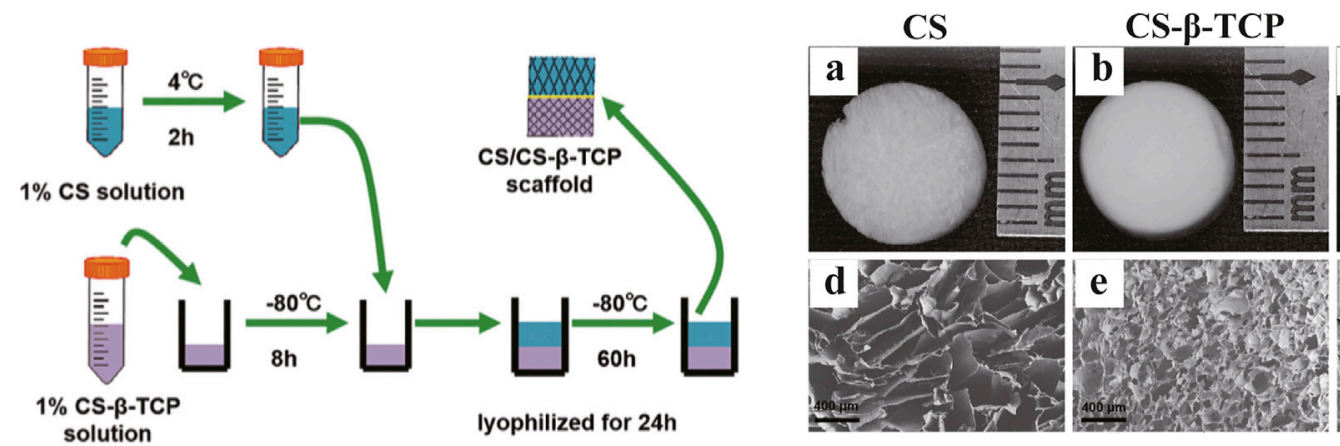

\section{Interface}
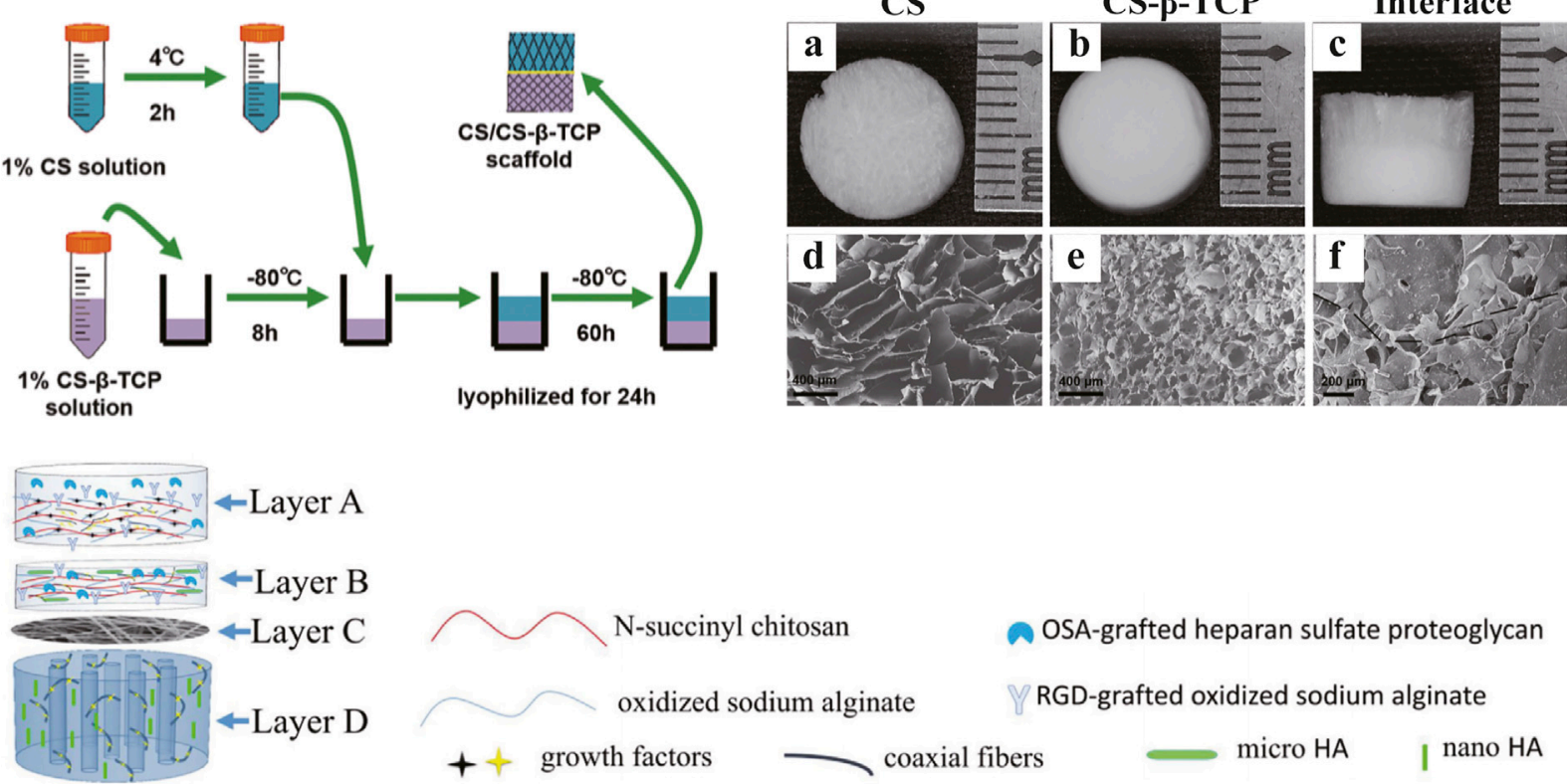

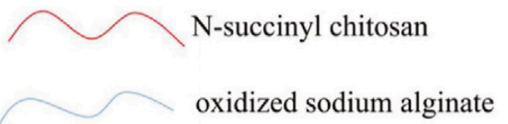

$+\downarrow$ growth factors $\longrightarrow$ coaxial fibers
OSA-grafted heparan sulfate proteoglycan

RGD-grafted oxidized sodium alginate

FIGURE 7 |Composite scaffolds. The fabrication process (A) and SEM images (B) of a bilayered composite scaffold consisting of $4 \%$ CHA cartilage layer (B: a) and $6 \%$ CA + 0.5\%HAp bone layer (B: $\mathbf{c})$ with an integrated interface (B: b). A bilayered CS/CS- $\beta$-TCP scaffold (C) was prepared and observed by gross appearance (C: a-c) and SEM (C: $\mathbf{d - f )}$. A composite scaffold with four functional layers improved the integration of implants with host tissues (D). (A and B) Adapted with permission from ref (Erickson et al., 2019). Copyright 2019 by Springer Science + Business Media LLC. (C) Adapted with permission from ref (Xu et al., 2021 ). Copyright 2021 by Mary Ann Liebert Inc. (D) Adapted with permission from ref (Chen et al., 2018). Copyright 2018 by Elsevier B.V.

three categories including bioinert materials (e.g., alumina and zirconia), semi-inert surface reactive materials (e.g., bioactive glass and dense hydroxyapatite) and biodegradable materials (e.g., calcium phosphate and tricalcium phosphate) (Pina et al., 2018). Unlike polymers, ceramics have better mechanical stiffness and corrosion resistance. However, several inherent features, such as fragility, inelasticity and difficult processing, limit their applications. Therefore, composite scaffolds made of polymers and ceramics perform better in mechanical properties and degradation behaviors. Erickson $\mathrm{AE}$ et al. presented a bilayered scaffold composed of two areas (Erickson et al.,
2019) (Figures 7A,B). The cartilage and bone layers contain chitosan/hyaluronic acid (HA) and chitosan/alginate/ hydroxyapatite nanorod (HAp), respectively. By the thermallyinduced phase separation process, a gradient transition zone between the two layers was established, improving the whole stability. A bilayered chitosan/chitosan- $\beta$-tricalcium phosphate (CS/CS- $\beta$-TCP) composite scaffold was fabricated and evaluated in a rat model (Xu et al., 2021) (Figure 7C). Cells seeded in both layers maintained excellent viability and differentiated into chondrogenic and osteogenic lineages, respectively. As one of the major projects in designing OC tissue engineering scaffolds, 
TABLE 3 | Hierarchical commercial products for OC tissue regeneration approved in the European Union.

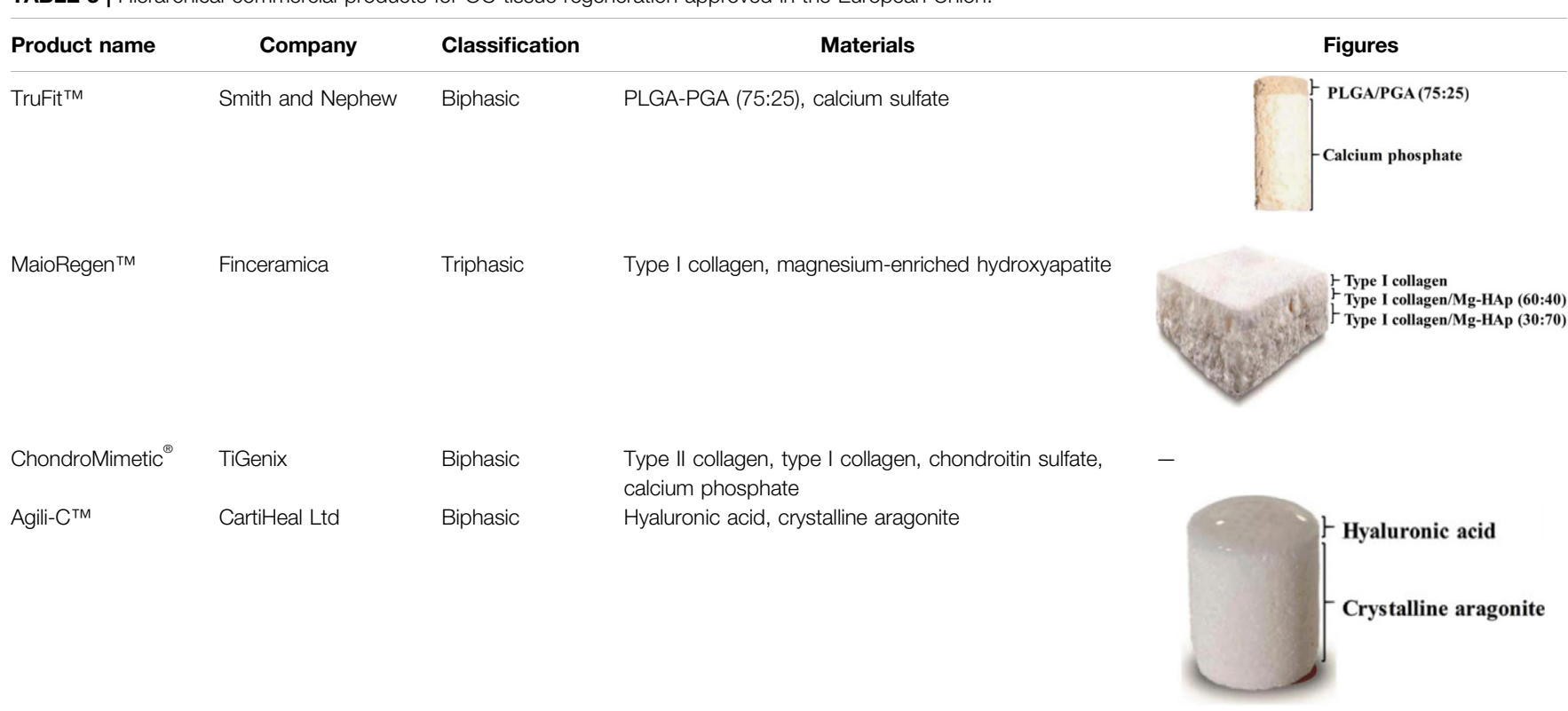

BioMatrix CRD Kensey Nash Biphasic Bovine collagen, $\beta$-TCP, PLA

Abbreviations: PLGA, poly(lactic-co-glycolic) acid; PGA, polyglycolic acid; PLA, polylactic acid. Figures were reprinted from ref (Zhang B et al., 2020) with permission from The Royal Society of Chemistry, Copyright 2020.

the bone-cartilage interface can regulate the mechanical properties of the composite structure and enhance the integration as a connecting medium. Meanwhile, the interface can inhibit unexpected infiltration and provide independent microenvironment for differentiation. For instance, a fourlayered composite scaffold was designed to improve the interfacial bonding between the newly formed tissues and the integration of implants with host tissues (Figure 7D). In the study by Khader $\mathrm{A}$ et al., fibrous zinc oxide $(\mathrm{ZnO}) / \mathrm{PCL}$ composite scaffolds were fabricated and evaluated in vitro (Khader and Arinzeh, 2020). Different percentage $\mathrm{ZnO}$ composite scaffolds demonstrated chondrogenic and osteogenic differentiations in different degrees. Bioactive glass (BG) is another important material to produce polymer-bioceramic composite scaffolds (Yao et al., 2014). Due to its osteogenic potential, BG has a remarkable application prospect in osteochondral defect repair. All these studies emphasize the value of composite scaffolds in effective osteochondral tissue engineering. At present, the main challenges in designing this type of scaffolds lie in the balance among stability, mechanical stiffness, biocompatibility, bioactivity and degradability.

\section{Extracellular Matrix-Based Scaffolds}

In consideration of the difficulty in mimicking comparable components and complicated architecture of native extracellular matrix (ECM), decellularization of specific tissues, by removing cells and genetic molecules and maintaining biochemical and biomechanical properties, is a potential candidate for scaffold fabrication in osteochondral tissue engineering (Hussey et al., 2018; Yin et al., 2018). Decellularized matrix derived from different tissues, such as urinary bladder, pericardium, dermis and cartilage etc., has been developed and investigated in vitro and in vivo (Singh et al., 2018; Bock et al., 2020). However, decellularized extracellular matrix (dECM), processed to serve as a whole scaffold, has several limitations. Due to the differences in tissue sources, separation and processing techniques and sterilization methods, decellularized scaffolds obtained have certain differences in structures and functions, limiting the reproducibility. Furthermore, unseeded scaffolds promote the natural rebuilding of host tissues, possibly resulting in poor tissue replacement and undesired inogenesis. Efforts should be made to control the potential negative outcomes. Besides, the recellularization of $\mathrm{dECM}$-based scaffolds to mimic native cell distribution is another challenge, considering cell type and concentration, seeding routes and methods and bioreaction characteristics (Hussey et al., 2018). Recently, studies on exosomes possibly pave a new way for OC tissue engineering strategies. Jiang $\mathrm{S}$ et al. applied cartilage dECM in combination with intra-articular injection of MSC derived exosomes for osteochondral tissue regeneration (Jiang et al., 2021).

\section{CLINICAL PRODUCTS}

To date, several synthetic scaffolds applied to osteochondral lesions have been translated into commercial products, some of which have been approved in the European Union, including TruFit $^{\mathrm{TM}}$, MaioRegen ${ }^{\mathrm{TM}}$, ChondroMimetic ${ }^{\circledR}$, BioMatrix CRD and Agili-C ${ }^{\mathrm{TM}}$ (Wang et al., 2020; D’Ambrosi et al., 2019; Getgood et al., 2012; Kon et al., 2016) (Table 3). Although these bilayered and multilayered scaffolds have reported considerable 

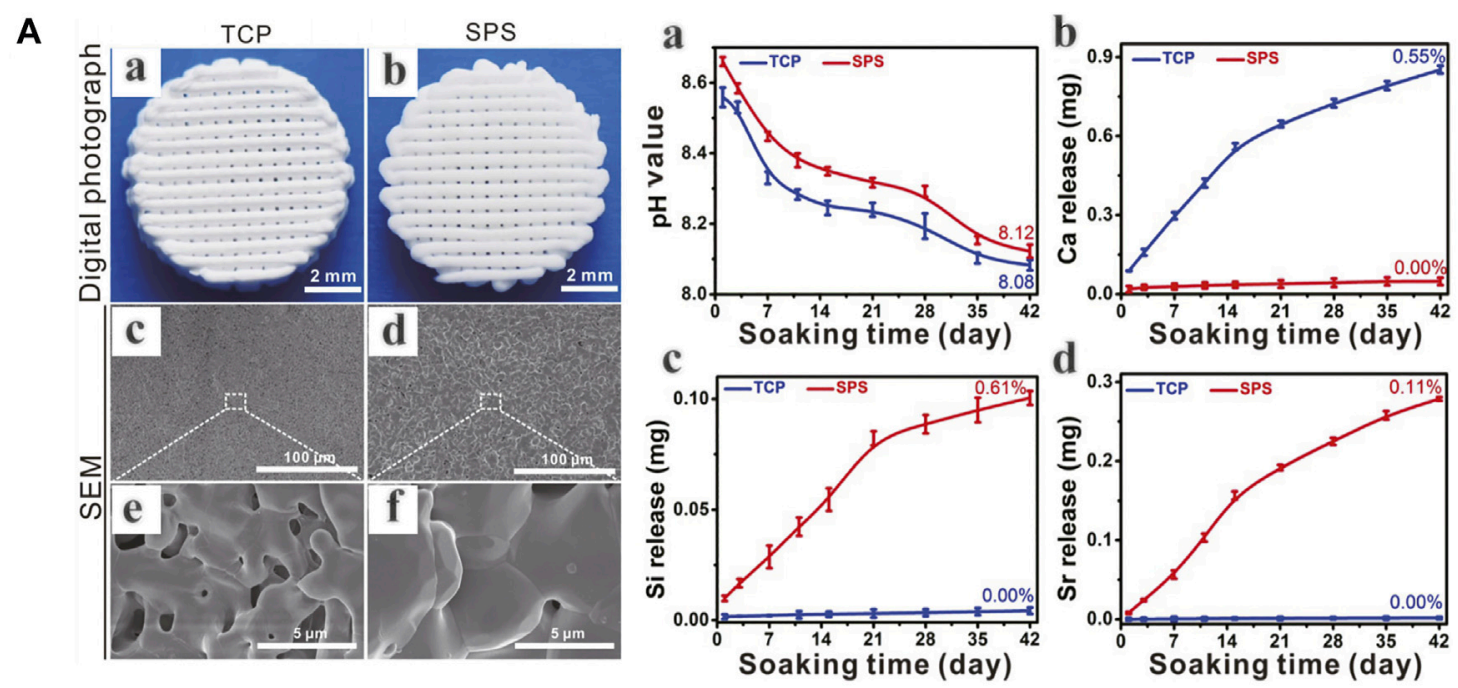

B

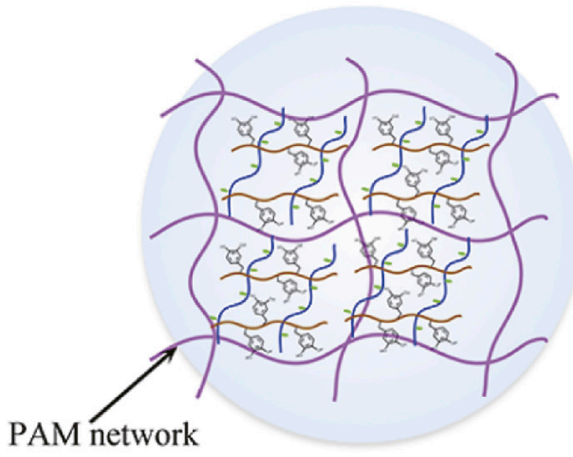

PDA-CS-PAM hydrogel

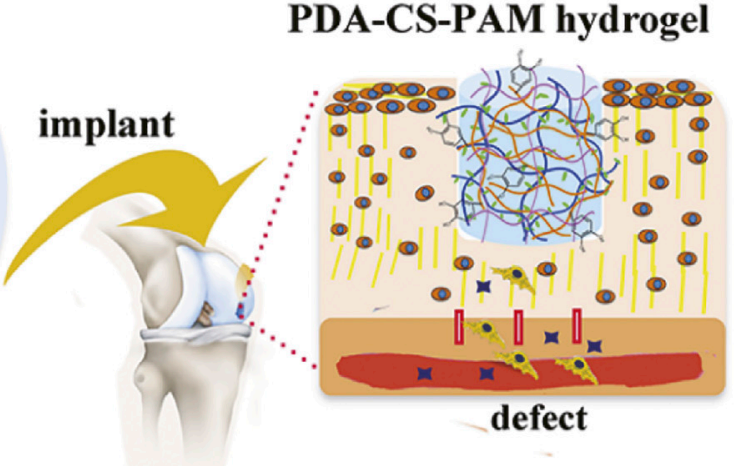

cartilage

FIGURE 8 | (A) 3D-printed $\mathrm{Sr}_{5}\left(\mathrm{PO}_{4}\right)_{2} \mathrm{SiO}_{4}$ (SPS) bioactive ceramic scaffolds can promote osteochondral defect reconstruction possibly by releasing Sr and $\mathrm{Si}$ ions (a-d). (B) A polydopamine-chondroitin sulfate-polyacrylamide (PDA-CS-PAM) hydrogel with tissue adhesiveness and super mechanical properties for cartilage regeneration. (A) Adapted with permission from ref (Deng et al., 2018). Copyright 2018 by Ivyspring International Publisher. (B) Adapted with permission from ref (Han et al., 2018). Copyright 2018 by American Chemical Society.

improvement in clinical symptoms and activity quality, several problems in clinical trials remain to be solved, such as the delamination of scaffolds, the incomplete integration with native tissue, the unsatisfactory quality of regenerated tissue, knee discomfort and the risk of reoperation etc. (Hindle et al., 2014; Brix et al., 2016; Farr et al., 2016; Azam et al., 2018). Therefore, further efforts are needed to illustrate the relationship between these problems and scaffold design strategies for volume production and clinical application.

\section{CURRENT CHALLENGES AND FUTURE PROSPECTS}

Due to the native complexity of OC tissue in hierarchical structure and biological functions, there are still several drawbacks and challenges remaining to be overcome, such as scaffold material-cell interactions, controlled cellular proliferation and differentiation, vascularization and long-term survival of the regenerated tissue etc. Chondrocytes are decisive to the maintenance of the structure and functions of cartilage tissue and can be seeded into scaffolds to produce cartilaginous extracellular matrix (ECM) (Malda et al., 2019). Considering the limitations of chondrocytes, such as isolation difficulty, low proliferation capacity, unexpected dedifferentiation and phenotypic instability, stem cells have offered a new kind of way for OC tissue regeneration. The respective chondrogenic and osteoblastic differentiation of stem cells depends on independent microenvironments, with the assistance of biological or physical stimulations or combined applications (Xuan et al., 2020; Paggi et al., 2020). The spatio-temporal control of stem cell differentiation is an important direction for further research. Due to the low survival rate of cells and instability of bioactive molecules, cells or growth factors incorporated scaffolds are difficult to store and transport, which is an obstacle to commercialization of bioactive scaffolds (Deng et al., 2018). 
Scaffolds in combination with multiple bioactive ions provide potential directions (Deng et al., 2018) (Figure 8A). Despite the hypothesis that MSCs can differentiate into chondrocytes to regenerate damaged tissue, their secretory functions have attracted more attention recently in tissue repair. Exosomes are possibly candidate for OC tissue engineering (Zhang et al., 2018). Besides, since cells and fibers in native OC tissue have gradient arrangements, the effects of filament orientations and constructs on cellular functions and tissue regeneration should be investigated (Zhang B et al., 2020). Moreover, the integration of scaffolds and regenerating tissue to surrounding targeted tissue is another consistent improving direction, determining the biomechanical properties of the composite structure (F. Zhou et al., 2018). Several strategies, including tissue adhesive and chemical modification, have been applied to enhance integration (Han et al., 2018; Zhang J et al., 2020) (Figure 8B). Despite the comprehensive understanding of the composition and structure of native OC tissue, the reconstruction of its anatomic and biomechanical gradients still remains difficult, which affects the long-term survival of newly formed tissue during joint movements. In comparison to the early developed monophasic scaffolds, biphasic scaffolds can achieve the regeneration of two individual layers, respectively, and triphasic scaffolds can better resemble the OC tissue stratification by taking intermediate CC layer into account. And recently proposed gradient scaffolds, whether in multiphasic or continuous forms, can better imitate the native biochemical components and architectural properties of OC tissue in a more superior way (Wei and Dai, 2021). As a potential direction in future studies, the development of sophisticated gradient OC tissue engineering scaffolds needs more exploration with the assistance of evolving biomaterials and fabrication techniques. Finally, good manufacturing practices and regulatory issues before and after clinical approval are critical to produce safe and efficacious commercial products (Zhou et al., 2020).

\section{CONCLUSION}

Over the past few decades, osteochondral tissue engineering strategies based on scaffolds have achieved great progress.

\section{REFERENCES}

Abarrategi, A., Gutiérrez, M. C., Moreno-Vicente, C., Hortigüela, M. J., Ramos, V., López-Lacomba, J. L., et al. (2008). Multiwall Carbon Nanotube Scaffolds for Tissue Engineering Purposes. Biomaterials 29, 94-102. doi:10.1016/ j.biomaterials.2007.09.021

Aguirre-Chagala, Y. E., Altuzar, V., León-Sarabia, E., Tinoco-Magaña, J. C., YañezLimón, J. M., and Mendoza-Barrera, C. (2017). Physicochemical Properties of Polycaprolactone/collagen/elastin Nanofibers Fabricated by Electrospinning. Mater. Sci. Eng. C 76, 897-907. Epub 2017 Mar 16. doi:10.1016/j.msec.2017.03.118

Algul, D., Sipahi, H., Aydin, A., Kelleci, F., Ozdatli, S., and Yener, F. G. (2015). Biocompatibility of Biomimetic Multilayered Alginate-Chitosan $/ \beta$-TCP Scaffold for Osteochondral Tissue. Int. J. Biol. Macromolecules 79, 363-369. Epub 2015 May 14. doi:10.1016/j.ijbiomac.2015.05.005

Ansari, S., Khorshidi, S., and Karkhaneh, A. (2019). Engineering of Gradient Osteochondral Tissue: From Nature to Lab. Acta Biomater. 87, 41-54. Epub 2019 Feb 2. doi:10.1016/j.actbio.2019.01.071
However, several problems still remain in the restoration of anatomical, biochemical and biomechanical stratification, including the efficiency of cells and bioactive molecules, the integration to adjacent tissues, the spatiotemporal control of physicochemical properties and cellular behaviors and the survival of regenerated tissue etc. In spite of all these challenges, we are optimistic that the development of closely related disciplines and further researches will gradually provide more opportunities for osteochondral tissue engineering for the foreseeable future.

\section{AUTHOR CONTRIBUTIONS}

J-NF, XW, and MY drafted the manuscript. Y-RC, J-YZ, R-HD, and Z-NZ collected and sorted the information. J-KY and F-ZY designed the conception and revised the manuscript. All the authors contributed to the article and approved the submitted version.

\section{FUNDING}

This research was funded by the National Natural Science Foundation of China (51920105006, 51773004, 52003008, and 51973226).

\section{SUPPLEMENTARY MATERIAL}

The Supplementary Material for this article can be found online at: https:/www.frontiersin.org/articles/10.3389/fbioe.2021.812383/ full\#supplementary-material

Figure S1 | The osteochondral (OC) tissue was observed with Safranin-O/Fast green staining in longitudinal (A) and cross (B) sections. And 3D-model of hyaline cartilage, calcified cartilage zone and subchondral bone was reconstructed. The lower interface of tidemark (C), the upper interface of tidemark (D), the upper interface of cement line $(E)$ and the lower interface of cement line $(F)$ were shown respectively. Scale bar: $200 \mu \mathrm{m}$. HC, hyaline cartilage; CCZ, calcified cartilage zone; SB, subchondral bone; TM, tidemark; CL, cement line. Adapted with permission from ref (Wang F et al., 2009). Copyright 2009 by Elsevier Inc.

Armiento, A. R., Stoddart, M. J., Alini, M., and Eglin, D. (2018). Biomaterials for Articular Cartilage Tissue Engineering: Learning from Biology. Acta Biomater. 65, 1-20. Epub 2017 Nov 8. doi:10.1016/j.actbio.2017.11.021

Azam, A., Forster, M., and Robertson, A. (2018). Clinical and Radiological Outcome for Trufit Plug in the Treatment of Chondral and Osteochondral Lesions at a Minimum of 2 Years. J. Orthopaedics 15, 47-51. doi:10.1016/ j.jor.2018.01.001

Baah-Dwomoh, A., Rolong, A., Gatenholm, P., and Davalos, R. V. (2015). The Feasibility of Using Irreversible Electroporation to Introduce Pores in Bacterial Cellulose Scaffolds for Tissue Engineering. Appl. Microbiol. Biotechnol. 99, 4785-4794. Epub 2015 Feb 18. doi:10.1007/s00253-0156445-0

Bajek, A., Olkowska, J., Gurtowska, N., Kloskowski, T., Walentowicz-Sadlecka, M., Sadlecki, P., et al. (2014). Human Amniotic-Fluid-Derived Stem Cells: a Unique Source for Regenerative Medicine. Expert Opin. Biol. Ther. 14, 831-839. Epub 2014 Mar 22. doi:10.1517/14712598.2014.898749

Baksh, D., Yao, R., and Tuan, R. S. (2007). Comparison of Proliferative and Multilineage Differentiation Potential of Human Mesenchymal Stem Cells 
Derived from Umbilical Cord and Bone Marrow. Stem Cells 25, 1384-1392. Epub 2007 Mar 1. doi:10.1634/stemcells.2006-0709

Barrett, A. N., Fong, C.-Y., Subramanian, A., Liu, W., Feng, Y., Choolani, M., et al. (2019). Human Wharton's Jelly Mesenchymal Stem Cells Show Unique Gene Expression Compared with Bone Marrow Mesenchymal Stem Cells Using Single-Cell RNA-Sequencing. Stem Cells Dev. 28, 196-211. Epub 2019 Jan 7. doi:10.1089/scd.2018.0132

Baumgartner, W., Otto, L., Hess, S. C., Stark, W. J., Märsmann, S., Bürgisser, G. M., et al. (2019). Cartilage/bone Interface Fabricated under Perfusion: Spatially Organized Commitment of Adipose-derived Stem Cells without Medium Supplementation. J. Biomed. Mater. Res. 107, 1833-1843. Epub 2018 Nov 21. doi:10.1002/jbm.b.34276

Bhardwaj, G., and Webster, T. (2016). Enhanced Chondrocyte Culture and Growth on Biologically Inspired Nanofibrous Cell Culture Dishes. Ijn 11, 479-483. doi:10.2147/IJN.S94000

Blair, H. C., Larrouture, Q. C., Li, Y., Lin, H., Beer-Stoltz, D., Liu, L., et al. (2017). Osteoblast Differentiation and Bone Matrix Formation In Vivo and In Vitro. Tissue Eng. B: Rev. 23, 268-280. Epub 2016 Dec 27. doi:10.1089/ ten.TEB.2016.0454

Bock, N., Pham, T. L.-B., Nguyen, T. B., Nguyen, T. B., Tran, H. A., and Tran, P. A. (2020). Polydopamine Coating of Uncrosslinked Chitosan as an Acellular Scaffold for Full Thickness Skin Grafts. Carbohydr. Polym. 245, 116524, 2020 . Epub 2020 Jun 3. doi:10.1016/j.carbpol.2020.116524

Boyer, C., Réthoré, G., Weiss, P., d'Arros, C., Lesoeur, J., Vinatier, C., et al. (2020). A Self-Setting Hydrogel of Silylated Chitosan and Cellulose for the Repair of Osteochondral Defects: From In Vitro Characterization to Preclinical Evaluation in Dogs. Front. Bioeng. Biotechnol. 8, 23. doi:10.3389/fbioe.2020.00023

Bozkurt, M., Aşık, M. D., Gürsoy, S., Türk, M., Karahan, S., Gümüşkaya, B., et al. (2019). Autologous Stem Cell-Derived Chondrocyte Implantation with BioTargeted Microspheres for the Treatment of Osteochondral Defects. J. Orthop. Surg. Res. 14, 394. doi:10.1186/s13018-019-1434-0

Brix, M., Kaipel, M., Kellner, R., Schreiner, M., Apprich, S., Boszotta, H., et al. (2016). Successful Osteoconduction but Limited Cartilage Tissue Quality Following Osteochondral Repair by a Cell-free Multilayered NanoComposite Scaffold at the Knee. Int. Orthopaedics (Sicot) 40, 625-632. Epub 2016 Jan 23. doi:10.1007/s00264-016-3118-2

Burr, D. B., and Gallant, M. A. (2012). Bone Remodelling in Osteoarthritis. Nat. Rev. Rheumatol. 8, 665-673. doi:10.1038/nrrheum.2012.130

Camci-Unal, G., Alemdar, N., Annabi, N., and Khademhosseini, A. (2013). Oxygen-releasing Biomaterials for Tissue Engineering. Polym. Int. 62, 843-848. doi:10.1002/pi.4502

Cao, T., Ho, K. H., and Teoh, S. H. (2003). Scaffold Design and In Vitro Study of Osteochondral Coculture in a Three-Dimensional Porous Polycaprolactone Scaffold Fabricated by Fused Deposition Modeling. Tissue Eng. 9, S103-S112. doi:10.1089/10763270360697012

Carballo, C. B., Nakagawa, Y., Sekiya, I., and Rodeo, S. A. (2017). Basic Science of Articular Cartilage. Clin. Sports Med. 36, 413-425. Epub 2017 Apr 26. doi:10.1016/j.csm.2017.02.001

Chaves, C., Alshomer, F., Palgrave, R. G., and Kalaskar, D. M. (2016). Plasma Surface Modification of Polyhedral Oligomeric Silsequioxane-Poly(carbonateUrea) Urethane with Allylamine Enhances the Response and Osteogenic Differentiation of Adipose-Derived Stem Cells. ACS Appl. Mater. Inter. 8, 18701-18709. Epub 2016 Jul 15. doi:10.1021/acsami.6b05788

Chen, C., Tambe, D. T., Deng, L., and Yang, L. (2013). Biomechanical Properties and Mechanobiology of the Articular Chondrocyte. Am. J. Physiology-Cell Physiol. 305, C1202-C1208. Epub 2013 Sep 25. doi:10.1152/ajpcell.00242.2013

Chen, M.-Y., Lie, P.-C., Li, Z.-L., and Wei, X. (2009). Endothelial Differentiation of Wharton's Jelly-Derived Mesenchymal Stem Cells in Comparison with Bone Marrow-Derived Mesenchymal Stem Cells. Exp. Hematol. 37, 629-640. doi:10.1016/j.exphem.2009.02.003

Chen, P., Tao, J., Zhu, S., Cai, Y., Mao, Q., Yu, D., et al. (2015). Radially Oriented Collagen Scaffold with SDF-1 Promotes Osteochondral Repair by Facilitating Cell Homing. Biomaterials 39, 114-123. Epub 2014 Nov 15. doi:10.1016/ j.biomaterials.2014.10.049

Chen, P., Zheng, L., Wang, Y., Tao, M., Xie, Z., Xia, C., et al. (2019). Desktopstereolithography 3D Printing of a Radially Oriented Extracellular Matrix/ mesenchymal Stem Cell Exosome Bioink for Osteochondral Defect Regeneration. Theranostics 9, 2439-2459. doi:10.7150/thno.31017
Chen, T., Bai, J., Tian, J., Huang, P., Zheng, H., and Wang, J. (2018). A Single Integrated Osteochondral In Situ Composite Scaffold with a Multi-Layered Functional Structure. Colloids Surf. B: Biointerfaces 167, 354-363. Epub 2018 Apr 16. doi:10.1016/j.colsurfb.2018.04.029

Cheng, A., Schwartz, Z., Kahn, A., Li, X., Shao, Z., Sun, M., et al. (2019). Advances in Porous Scaffold Design for Bone and Cartilage Tissue Engineering and Regeneration. Tissue Eng. Part B: Rev. 25, 14-29. Epub 2018 Sep 20. doi:10.1089/ten.TEB.2018.0119

Coryell, P. R., Diekman, B. O., and Loeser, R. F. (2021). Mechanisms and Therapeutic Implications of Cellular Senescence in Osteoarthritis. Nat. Rev. Rheumatol. 17, 47-57. Epub 2020 Nov 18. doi:10.1038/s41584-020-00533-7

Costantini, M., Colosi, C., Mozetic, P., Jaroszewicz, J., Tosato, A., Rainer, A., et al. (2016). Correlation between Porous Texture and Cell Seeding Efficiency of Gas Foaming and Microfluidic Foaming Scaffolds. Mater. Sci. Eng. C 62, 668-677. Epub 2016 Feb 5. doi:10.1016/j.msec.2016.02.010

Cross, L. M., Thakur, A., Jalili, N. A., Detamore, M., and Gaharwar, A. K. (2016). Nanoengineered Biomaterials for Repair and Regeneration of Orthopedic Tissue Interfaces. Acta Biomater. 42, 2-17. Epub 2016 Jun 17. doi:10.1016/ j.actbio.2016.06.023

Da, H., Jia, S.-J., Meng, G.-L., Cheng, J.-H., Zhou, W., Xiong, Z., et al. (2013). The Impact of Compact Layer in Biphasic Scaffold on Osteochondral Tissue Engineering. PLoS One 8, e54838, 2013 . Epub 2013 Jan 28. doi:10.1371/ journal.pone. 0054838

D’Ambrosi, R., Valli, F., De Luca, P., Ursino, N., and Usuelli, F. (2019). MaioRegen Osteochondral Substitute for the Treatment of Knee Defects: A Systematic Review of the Literature. $J \mathrm{~cm}$ 8, 783. doi:10.3390/jcm8060783

Degirmenci, E., Ozturan, K. E., Sahin, A. A., Yilmaz, F., and Kaya, Y. E. (2019). Effects of Tranexamic Acid on the Recovery of Osteochondral Defects Treated by Microfracture and Acellular Matrix Scaffold: an Experimental Study. J. Orthop. Surg. Res. 14, 105. doi:10.1186/s13018-019-1144-7

Dehghani Nazhvani, F., Mohammadi Amirabad, L., Azari, A., Namazi, H., Hosseinzadeh, S., Samanipour, R., et al. (2021). Effects of In Vitro Low Oxygen Tension Preconditioning of Buccal Fat Pad Stem Cells on In Vivo Articular Cartilage Tissue Repair. Life Sci. 280, 119728, 2021 . Epub 2021 Jun 16. doi:10.1016/j.lfs.2021.119728

Deng, C., Chang, J., and Wu, C. (2019). Bioactive Scaffolds for Osteochondral Regeneration. J. Orthopaedic Translation 17, 15-25. doi:10.1016/j.jot.2018.11.006

Deng, C., Zhu, H., Li, J., Feng, C., Yao, Q., Wang, L., et al. (2018). Bioactive Scaffolds for Regeneration of Cartilage and Subchondral Bone Interface. Theranostics 8, 1940-1955. doi:10.7150/thno.23674

Di Luca, A., Van Blitterswijk, C., and Moroni, L. (2015). The Osteochondral Interface as a Gradient Tissue: from Development to the Fabrication of Gradient Scaffolds for Regenerative Medicine. Birth Defect Res. C 105, 34-52. Epub 2015 Mar 16. doi:10.1002/bdrc.21092

Díaz Lantada, A., Alarcón Iniesta, H., and García-Ruíz, J. P. (2016). Composite Scaffolds for Osteochondral Repair Obtained by Combination of Additive Manufacturing, Leaching Processes and hMSC-CM Functionalization, Mater. Sci. Eng. C 59, 218-227. Epub 2015 Oct 8. doi:10.1016/ j.msec.2015.10.015

Ding, C., Qiao, Z., Jiang, W., Li, H., Wei, J., Zhou, G., et al. (2013). Regeneration of a Goat Femoral Head Using a Tissue-specific, Biphasic Scaffold Fabricated with CAD/CAM Technology. Biomaterials 34, 6706-6716. Epub 2013 Jun 14. doi:10.1016/j.biomaterials.2013.05.038

Ding, J., Chen, B., Lv, T., Liu, X., Fu, X., Wang, Q., et al. (2016). Bone Marrow Mesenchymal Stem Cell-Based Engineered Cartilage Ameliorates Polyglycolic Acid/Polylactic Acid Scaffold-Induced Inflammation through M2 Polarization of Macrophages in a Pig Model. STEM CELLS Translational Med. 5, 1079-1089. Epub 2016 Jun 8. doi:10.5966/sctm.2015-0263

Dormer, N. H., Singh, M., Wang, L., Berkland, C. J., and Detamore, M. S. (2010). Osteochondral Interface Tissue Engineering Using Macroscopic Gradients of Bioactive Signals. Ann. Biomed. Eng. 38, 2167-2182. Epub 2010 Apr 9. doi:10.1007/s10439-010-0028-0

Dresing, I., Zeiter, S., Auer, J., Alini, M., and Eglin, D. (2014). Evaluation of a PressFit Osteochondral Poly(ester-Urethane) Scaffold in a Rabbit Defect Model. J. Mater. Sci. Mater. Med. 25, 1691-1700. Epub 2014 Mar 26. doi:10.1007/ s10856-014-5192-6

Duan, P., Pan, Z., Cao, L., He, Y., Wang, H., Qu, Z., et al. (2014). The Effects of Pore Size in Bilayered Poly(lactide-Co-Glycolide) Scaffolds on Restoring 
Osteochondral Defects in Rabbits. J. Biomed. Mater. Res. 102, 180-192. Epub 2013 May 2. doi:10.1002/jbm.a.34683

Duan, X., Zhu, X., Dong, X., Yang, J., Huang, F., Cen, S., et al. (2013). Repair of Large Osteochondral Defects in a Beagle Model with a Novel Type I Collagen/ glycosaminoglycan-Porous Titanium Biphasic Scaffold. Mater. Sci. Eng. C 33, 3951-3957. Epub 2013 May 25. doi:10.1016/j.msec.2013.05.040

Elangomannan, S., Louis, K., Dharmaraj, B. M., Kandasamy, V. S., Soundarapandian, K., and Gopi, D. (2017). Carbon Nanofiber/ Polycaprolactone/Mineralized Hydroxyapatite Nanofibrous Scaffolds for Potential Orthopedic Applications. ACS Appl. Mater. Inter. 9, 6342-6355. Epub 2017 Feb 10. doi:10.1021/acsami.6b13058

Erickson, A. E., Sun, J., Lan Levengood, S. K., Swanson, S., Chang, F.-C., Tsao, C. T., et al. (2019). Chitosan-based Composite Bilayer Scaffold as an In Vitro Osteochondral Defect Regeneration Model. Biomed. Microdevices 21, 34. doi:10.1007/s10544-019-0373-1

Erisken, C., Kalyon, D. M., Wang, H., Örnek-Ballanco, C., and Xu, J. (2011). Osteochondral Tissue Formation through Adipose-Derived Stromal Cell Differentiation on Biomimetic Polycaprolactone Nanofibrous Scaffolds with Graded Insulin and Beta-Glycerophosphate Concentrations. Tissue Eng. A 17, 1239-1252. Epub 2011 Feb 3. doi:10.1089/ten.TEA.2009.0693

Fang, Y., Yang, X., Lin, Y., Shi, J., Prominski, A., Clayton, C., et al. (2021). Dissecting Biological and Synthetic Soft-Hard Interfaces for Tissue-like Systems. Chem. Rev. Epub ahead of print. doi:10.1021/acs.chemrev.1c00365

Farooqi, A. R., Bader, R., and van Rienen, U. (2019). Numerical Study on Electromechanics in Cartilage Tissue with Respect to its Electrical Properties. Tissue Eng. Part B: Rev. 25, 152-166. Epub 2018 Dec 31. doi:10.1089/ten.TEB.2018.0214

Farr, J., Gracitelli, G. C., Shah, N., Chang, E. Y., and Gomoll, A. H. (2016). High Failure Rate of a Decellularized Osteochondral Allograft for the Treatment of Cartilage Lesions. Am. J. Sports Med. 44, 2015-2022. Epub. doi:10.1177/ 0363546516645086

Fell, N. L. A., Lawless, B. M., Cox, S. C., Cooke, M. E., Eisenstein, N. M., Shepherd, D. E. T., et al. (2019). The Role of Subchondral Bone, and its Histomorphology, on the Dynamic Viscoelasticity of Cartilage, Bone and Osteochondral Cores. Osteoarthritis and Cartilage 27, 535-543. Epub 2018 Dec 18. doi:10.1016/ j.joca.2018.12.006

Ferguson, V. L., Bushby, A. J., and Boyde, A. (2003). Nanomechanical Properties and mineral Concentration in Articular Calcified Cartilage and Subchondral Bone. J. Anat. 203, 191-202. doi:10.1046/j.1469-7580.2003.00193.x

Florencio-Silva, R., Sasso, G. R. d. S., Sasso-Cerri, E., Simões, M. J., and Cerri, P. S. (2015). Biology of Bone Tissue: Structure, Function, and Factors that Influence Bone Cells. Biomed. Res. Int. 2015, 1-17. Epub 2015 Jul 13. doi:10.1155/2015/ 421746

Furuya, M., Kikuta, J., Fujimori, S., Seno, S., Maeda, H., Shirazaki, M., et al. (2018). Direct Cell-Cell Contact between Mature Osteoblasts and Osteoclasts Dynamically Controls Their Functions In Vivo. Nat. Commun. 9, 300. doi:10.1038/s41467-017-02541-w

Gao, F., Xu, Z., Liang, Q., Li, H., Peng, L., Wu, M., et al. (2019). Osteochondral Regeneration with 3D-Printed Biodegradable High-Strength Supramolecular Polymer Reinforced-Gelatin Hydrogel Scaffolds. Adv. Sci. 6, 1900867. doi:10.1002/advs.201900867

Gao, P., Jiang, D., Liu, W., Li, H., and Li, Z. (2016). Urine-derived Stem Cells, A New Source of Seed Cells for Tissue Engineering. Cscr 11, 547-553. doi:10.2174/ $1574888 \times 10666150220161506$

Getgood, A., Henson, F., Skelton, C., Herrera, E., Brooks, R., Fortier, L. A., et al. (2012). The Augmentation of a Collagen/Glycosaminoglycan Biphasic Osteochondral Scaffold with Platelet-Rich Plasma and Concentrated Bone Marrow Aspirate for Osteochondral Defect Repair in Sheep. Cartilage 3, 351-363. doi:10.1177/1947603512444597

Gibbs, D. M., Vaezi, M., Yang, S., and Oreffo, R. O. (2014). Hope versus Hype: what Can Additive Manufacturing Realistically Offer Trauma and Orthopedic Surgery? Regenerative Med. 9, 535-549. doi:10.2217/rme.14.20

Goldring, M. B., and Goldring, S. R. (2010). Articular Cartilage and Subchondral Bone in the Pathogenesis of Osteoarthritis. Ann. N. Y Acad. Sci. 1192, 230-237. doi:10.1111/j.1749-6632.2009.05240.x

Goldring, S. R., and Goldring, M. B. (2016). Changes in the Osteochondral Unit during Osteoarthritis: Structure, Function and Cartilage-Bone Crosstalk. Nat. Rev. Rheumatol. 12, 632-644. doi:10.1038/nrrheum.2016.148
Gonçalves, A. M., Moreira, A., Weber, A., Williams, G. R., and Costa, P. F. (2021). Osteochondral Tissue Engineering: The Potential of Electrospinning and Additive Manufacturing. Pharmaceutics 13, 983. doi:10.3390/ pharmaceutics13070983

Gracitelli, G. C., Moraes, V. Y., Franciozi, C. E., Luzo, M. V., and Belloti, J. C. (2016). Surgical Interventions (Microfracture, Drilling, Mosaicplasty, and Allograft Transplantation) for Treating Isolated Cartilage Defects of the Knee in Adults. Cochrane Database Syst. Rev. 9, CD010675. doi:10.1002/ 14651858.CD010675.pub2

Griffin, M. F., Ibrahim, A., Seifalian, A. M., Butler, P. E. M., Kalaskar, D. M., and Ferretti, P. (2017). Chemical Group-dependent Plasma Polymerisation Preferentially Directs Adipose Stem Cell Differentiation towards Osteogenic or Chondrogenic Lineages. Acta Biomater. 50, 450-461. Epub 2016 Dec 9. doi:10.1016/j.actbio.2016.12.016

Guan, J.-J., Niu, X., Gong, F.-X., Hu, B., Guo, S.-C., Lou, Y.-L., et al. (2014). Biological Characteristics of Human-Urine-Derived Stem Cells: Potential for Cell-Based Therapy in Neurology. Tissue Eng. Part A 20, 1794-1806. Epub 2014 May 19. doi:10.1089/ten.TEA.2013.0584

Han, F., Zhou, F., Yang, X., Zhao, J., Zhao, Y., and Yuan, X. (2015). A Pilot Study of Conically Graded Chitosan-Gelatin Hydrogel/PLGA Scaffold with DualDelivery of TGF-B1 and BMP-2 for Regeneration of Cartilage-Bone Interface. J. Biomed. Mater. Res. 103, 1344-1353. Epub 2014 Nov 11. doi:10.1002/jbm.b.33314

Han, L., Wang, M., Li, P., Gan, D., Yan, L., Xu, J., et al. (2018). Mussel-Inspired Tissue-Adhesive Hydrogel Based on the Polydopamine-Chondroitin Sulfate Complex for Growth-factor-free Cartilage Regeneration. ACS Appl. Mater. Inter. 10, 28015-28026. Epub 2018 Aug 10. doi:10.1021/acsami.8b05314

He, J., Hu, X., Cao, J., Zhang, Y., Xiao, J., Peng, l., et al. (2021). Chitosan-coated Hydroxyapatite and Drug-Loaded Polytrimethylene Carbonate/polylactic Acid Scaffold for Enhancing Bone Regeneration. Carbohydr. Polym. 253, 117198, 2021 . Epub 2020 Oct 10. doi:10.1016/j.carbpol.2020.117198

He, Q., Zhang, J., Liao, Y., Alakpa, E. V., Bunpetch, V., Zhang, J., et al. (2020). Current Advances in Microsphere Based Cell Culture and Tissue Engineering. Biotechnol. Adv. 39, 107459, 2020 . Epub 2019 Nov 1. doi:10.1016/ j.biotechadv.2019.107459

Hild, N., Schneider, O. D., Mohn, D., Luechinger, N. A., Koehler, F. M., Hofmann, S., et al. (2011). Two-layer Membranes of Calcium Phosphate/collagen/PLGA Nanofibres: In Vitro Biomineralisation and Osteogenic Differentiation of Human Mesenchymal Stem Cells. Nanoscale 3, 401-409. Epub 2010 Nov 9. doi:10.1039/c0nr00615g

Hindle, P., Hendry, J. L., Keating, J. F., and Biant, L. C. (2014). Autologous Osteochondral Mosaicplasty or TruFit Plugs for Cartilage Repair. Knee Surg. Sports Traumatol. Arthrosc. 22, 1235-1240. Epub 2013 Apr 16. doi:10.1007/ s00167-013-2493-0

Hossain, M. S., Bergstrom, D. J., and Chen, X. B. (2015). Modelling and Simulation of the Chondrocyte Cell Growth, Glucose Consumption and Lactate Production within a Porous Tissue Scaffold inside a Perfusion Bioreactor. Biotechnol. Rep. 5, 55-62. doi:10.1016/j.btre.2014.12.002

Hu, K., and Olsen, B. R. (2016). Osteoblast-derived VEGF Regulates Osteoblast Differentiation and Bone Formation during Bone Repair. J. Clin. Invest. 126, 509-526. doi:10.1172/JCI82585

Hu, Y., Chen, X., Wang, S., Jing, Y., and Su, J. (2021). Subchondral Bone Microenvironment in Osteoarthritis and Pain. Bone Res. 9, 20. doi:10.1038/ s41413-021-00147-z

Huebsch, N., Lippens, E., Lee, K., Mehta, M., Koshy, S. T., Darnell, M. C., et al. (2015). Matrix Elasticity of Void-Forming Hydrogels Controls TransplantedStem-Cell-Mediated Bone Formation. Nat. Mater 14, 1269-1277. doi:10.1038/ nmat 4407

Hunter, D. J., and Bierma-Zeinstra, S. (2019). Osteoarthritis. The Lancet 393, 1745-1759. doi:10.1016/S0140-6736(19)30417-9

Hunziker, E. B., Quinn, T. M., and Häuselmann, H.-J. (2002). Quantitative Structural Organization of normal Adult Human Articular Cartilage. Osteoarthritis and Cartilage 10, 564-572. doi:10.1053/joca.2002.0814

Hussey, G. S., Dziki, J. L., and Badylak, S. F. (2018). Extracellular Matrix-Based Materials for Regenerative Medicine. Nat. Rev. Mater. 3, 159-173. doi:10.1038/ s41578-018-0023-x

Hutmacher, D. W. (2000). Scaffolds in Tissue Engineering Bone and Cartilage. Biomaterials 21, 2529-2543. doi:10.1016/s0142-9612(00)00121-6 
Jacob, J., More, N., Kalia, K., and Kapusetti, G. (2018). Piezoelectric Smart Biomaterials for Bone and Cartilage Tissue Engineering. Inflamm. Regener 38, 2. doi:10.1186/s41232-018-0059-8

Jeon, J. E., Vaquette, C., Theodoropoulos, C., Klein, T. J., and Hutmacher, D. W. (2014). Multiphasic Construct Studied in an Ectopic Osteochondral Defect Model. J. R. Soc. Interf. 11, 20140184. doi:10.1098/rsif.2014.0184

Jia, S., Wang, J., Zhang, T., Pan, W., Li, Z., He, X., et al. (2018). Multilayered Scaffold with a Compact Interfacial Layer Enhances Osteochondral Defect Repair. ACS Appl. Mater. Inter. 10, 20296-20305. Epub 2018 Jun 5. doi:10.1021/ acsami.8b03445

Jiang, J., Tang, A., Ateshian, G. A., Guo, X. E., Hung, C. T., and Lu, H. H. (2010). Bioactive Stratified Polymer Ceramic-Hydrogel Scaffold for Integrative Osteochondral Repair. Ann. Biomed. Eng. 38, 2183-2196. Epub 2010 Apr 22. doi:10.1007/s10439-010-0038-y

Jiang, S., Tian, G., Yang, Z., Gao, X., Wang, F., Li, J., et al. (2021). Enhancement of Acellular Cartilage Matrix Scaffold by Wharton's Jelly Mesenchymal Stem CellDerived Exosomes to Promote Osteochondral Regeneration. Bioactive Mater. 6, 2711-2728. doi:10.1016/j.bioactmat.2021.01.031

Jiang, Y., Chen, L., Zhang, S., Tong, T., Zhang, W., Liu, W., et al. (2013). Incorporation of Bioactive Polyvinylpyrrolidone-Iodine within Bilayered Collagen Scaffolds Enhances the Differentiation and Subchondral Osteogenesis of Mesenchymal Stem Cells. Acta Biomater. 9, 8089-8098. Epub 2013 May 23. doi:10.1016/j.actbio.2013.05.014

Kagami, H., Agata, H., and Tojo, A. (2011). Bone Marrow Stromal Cells (Bone Marrow-Derived Multipotent Mesenchymal Stromal Cells) for Bone Tissue Engineering: Basic Science to Clinical Translation. Int. J. Biochem. Cell Biol. 43, 286-289. Epub 2010 Dec 13. doi:10.1016/j.biocel.2010.12.006

Kandel, R. A., Grynpas, M., Pilliar, R., Lee, J., Wang, J., Waldman, S., et al. (2006). CIHR-bioengineering of Skeletal Tissues TeamRepair of Osteochondral Defects with Biphasic Cartilage-Calcium Polyphosphate Constructs in a Sheep Model. Biomaterials 27, 4120-4131. Epub 2006 Mar 29. doi:10.1016/ j.biomaterials.2006.03.005

Karkhaneh, A., Naghizadeh, Z., Shokrgozar, M. A., Bonakdar, S., Solouk, A., and Haghighipour, N. (2014). Effects of Hydrostatic Pressure on Biosynthetic Activity during Chondrogenic Differentiation of MSCs in Hybrid Scaffolds. Int. J. Artif. Organs 37, 142-148. Epub 2014 Feb 7. doi:10.5301/ijao.5000288

Karner, C. M., and Long, F. (2018). Glucose Metabolism in Bone. Bone 115, 2-7. Epub 2017 Aug 24. doi:10.1016/j.bone.2017.08.008

Khader, A., and Arinzeh, T. L. (2020). Biodegradable Zinc Oxide Composite Scaffolds Promote Osteochondral Differentiation of Mesenchymal Stem Cells. Biotechnol. Bioeng. 117, 194-209. Epub 2019 Oct 6. doi:10.1002/bit.27173

Khorshidi, S., and Karkhaneh, A. (2018). A Review on Gradient Hydrogel/fiber Scaffolds for Osteochondral Regeneration. J. Tissue Eng. Regen. Med. 12, e1974-e1990. Epub 2018 Jan 28. doi:10.1002/term.2628

Kim, H. S., Mandakhbayar, N., Kim, H.-W., Leong, K. W., and Yoo, H. S. (2021). Protein-reactive Nanofibrils Decorated with Cartilage-Derived Decellularized Extracellular Matrix for Osteochondral Defects. Biomaterials 269, 120214, 2021 . Epub 2020 Jun 27. doi:10.1016/j.biomaterials.2020.120214

Kim, S. H., Kim, S. H., and Jung, Y. (2015). Bi-layered PLCL/(PLGA/ $\beta$-TCP) Composite Scaffold for Osteochondral Tissue Engineering. J. Bioactive Compatible Polym. 30, 178-187. doi:10.1177/0883911514566015

Kim, T. W., Lee, M. C., Bae, H. C., and Han, H. S. (2018). Direct Coculture of Human Chondrocytes and Synovium-Derived Stem Cells Enhances In Vitro Chondrogenesis. Cell J 20, 53-60. doi:10.22074/cellj.2018.5025

Kim, Y. G., Choi, J., and Kim, K. (2020). Mesenchymal Stem Cell-Derived Exosomes for Effective Cartilage Tissue Repair and Treatment of Osteoarthritis. Biotechnol. J. 15, 2000082, 2020 . Epub 2020 Jul 13. doi:10.1002/biot.202000082

Knothe Tate, M. L., Adamson, J. R., Tami, A. E., and Bauer, T. W. (2004). The Osteocyte. Int. J. Biochem. Cell Biol. 36, 1-8. doi:10.1016/s1357-2725(03) 00241-3

Komori, T. (2016). Cell Death in Chondrocytes, Osteoblasts, and Osteocytes. Ijms 17, 2045. doi:10.3390/ijms17122045

Komori, T. (2019). Regulation of Proliferation, Differentiation and Functions of Osteoblasts by Runx2. Ijms 20, 1694. doi:10.3390/ijms20071694

Kon, E., Robinson, D., Verdonk, P., Drobnic, M., Patrascu, J. M., Dulic, O., et al. (2016). A Novel Aragonite-Based Scaffold for Osteochondral Regeneration:
Early Experience on Human Implants and Technical Developments. Injury 47 (Suppl. 6), S27-S32. doi:10.1016/S0020-1383(16)30836-1

Kreipke, T. C., and Niebur, G. L. (2017). Anisotropic Permeability of Trabecular Bone and its Relationship to Fabric and Architecture: A Computational Study. Ann. Biomed. Eng. 45, 1543-1554. Epub 2017 Feb 2. doi:10.1007/s10439-017-1805-9

Kwon, H., Brown, W. E., Lee, C. A., Wang, D., Paschos, N., Hu, J. C., et al. (2019). Surgical and Tissue Engineering Strategies for Articular Cartilage and Meniscus Repair. Nat. Rev. Rheumatol. 15, 550-570. Epub 2019 Jul 11. doi:10.1038/s41584-019-0255-1

Le, T. M., Vu, N. B., Huynh, P. D., and Van Pham, P. (2021). Treatment of Osteochondral Femoral Head Defect by Human Umbilical Cord Mesenchymal Stem Cell Sheet Transplantation: An Experimental Study in Rats. Adv. Exp. Med. Biol. Epub ahead of print. doi:10.1007/5584_2021_671

Levingstone, T. J., Thompson, E., Matsiko, A., Schepens, A., Gleeson, J. P., and O’Brien, F. J. (2016). Multi-layered Collagen-Based Scaffolds for Osteochondral Defect Repair in Rabbits. Acta Biomater. 32, 149-160. Epub 2015 Dec 24. doi:10.1016/j.actbio.2015.12.034

Li, C., Ouyang, L., Armstrong, J. P. K., and Stevens, M. M. (2021). Advances in the Fabrication of Biomaterials for Gradient Tissue Engineering. Trends Biotechnol. 39, 150-164. Epub 2020 Jul 7. doi:10.1016/j.tibtech.2020.06.005

Liao, J., Tian, T., Shi, S., Xie, X., Ma, Q., Li, G., et al. (2017). The Fabrication of Biomimetic Biphasic CAN-PAC Hydrogel with a Seamless Interfacial Layer Applied in Osteochondral Defect Repair. Bone Res. 5, 17018. doi:10.1038/ boneres.2017.18

Lin, L., Wang, T., Zhou, Q., and Qian, N. (2016). The Effects of Different Amounts of Drug Microspheres on the Vivo and Vitro Performance of the PLGA/ $\beta$-TCP Scaffold. Designed Monomers Polym. 20, 351-362. doi:10.1080/ 15685551.2016.1259839

Liu, S., Wu, J., Liu, X., Chen, D., Bowlin, G. L., Cao, L., et al. (2015). Osteochondral Regeneration Using an Oriented Nanofiber Yarn-Collagen Type I/hyaluronate Hybrid/TCP Biphasic Scaffold. J. Biomed. Mater. Res. 103, 581-592. Epub 2014 May 7. doi:10.1002/jbm.a.35206

Liu, S., Yuan, M., Hou, K., Zhang, L., Zheng, X., Zhao, B., et al. (2012). Immune Characterization of Mesenchymal Stem Cells in Human Umbilical Cord Wharton's Jelly and Derived Cartilage Cells. Cell Immunol. 278, 35-44. Epub 2012 Jul 16. doi:10.1016/j.cellimm.2012.06.010

Liu, W., Lipner, J., Moran, C. H., Feng, L., Li, X., Thomopoulos, S., et al. (2015). Generation of Electrospun Nanofibers with Controllable Degrees of Crimping through a Simple, Plasticizer-Based Treatment. Adv. Mater. 27, 2583-2588. Epub 2015 Mar 10. doi:10.1002/adma.201500329

Liu, Y.-Y., Yu, H.-C., Liu, Y., Liang, G., Zhang, T., and Hu, Q.-X. (2016). Dual Drug Spatiotemporal Release from Functional Gradient Scaffolds Prepared Using 3D Bioprinting and Electrospinning. Polym. Eng. Sci. 56, 170-177. doi:10.1002/ pen. 24239

Loeser, R. F. (2014). Integrins and Chondrocyte-Matrix Interactions in Articular Cartilage. Matrix Biol. 39, 11-16. Epub 2014 Aug 25. doi:10.1016/ j.matbio.2014.08.007

Lyons, T. J., McClure, S. F., Stoddart, R. W., and McClure, J. (2006). The normal Human Chondro-Osseous Junctional Region: Evidence for Contact of Uncalcified Cartilage with Subchondral Bone and Marrow Spaces. BMC Musculoskelet. Disord. 7, 52. doi:10.1186/1471-2474-7-52

M, J. C., Konwarh, R., Knowles, J. C., and Mandal, B. B. (2017). Mimicking Hierarchical Complexity of the Osteochondral Interface Using Electrospun Silk-Bioactive Glass Composites. ACS Appl. Mater. Inter. 9, 8000-8013. Epub 2017 Feb 22. doi:10.1021/acsami.6b16590

Ma, K., Zhao, T., Yang, L., Wang, P., Jin, J., Teng, H., et al. (2020). Application of Robotic-Assisted In Situ 3D Printing in Cartilage Regeneration with HAMA Hydrogel: An In Vivo Study. J. Adv. Res. 23, 123-132. doi:10.1016/ j.jare.2020.01.010

Ma, N., Wang, H., Xu, X., Wan, Y., Liu, Y., Wang, M., et al. (2017). Autologouscell-derived, Tissue-Engineered Cartilage for Repairing Articular Cartilage Lesions in the Knee: Study Protocol for a Randomized Controlled Trial. Trials 18, 519. doi:10.1186/s13063-017-2251-6

Madry, H., Venkatesan, J. K., Carballo-Pedrares, N., Rey-Rico, A., and Cucchiarini, M. (2020). Scaffold-Mediated Gene Delivery for Osteochondral Repair. Pharmaceutics 12, 930. doi:10.3390/pharmaceutics 12100930

Mahmoudifar, N., and Doran, P. M. (2013). Osteogenic Differentiation and Osteochondral Tissue Engineering Using Human Adipose-Derived Stem 
Cells. Biotechnol. Prog. 29, 176-185. Epub 2012 Dec 20. doi:10.1002/ btpr. 1663

Maia, F. R., Carvalho, M. R., Oliveira, J. M., and Reis, R. L. (2018). Tissue Engineering Strategies for Osteochondral Repair. Adv. Exp. Med. Biol. 1059, 353-371. doi:10.1007/978-3-319-76735-2_16

Malda, J., Groll, J., and van Weeren, P. R. (2019). Rethinking Articular Cartilage Regeneration Based on a 250-Year-Old Statement. Nat. Rev. Rheumatol. 15, 571-572. doi:10.1038/s41584-019-0278-7

Maleki, M., Hashlamoun, K., Herzog, W., and Federico, S. (2020). Effect of Structural Distortions on Articular Cartilage Permeability under Large Deformations. Biomech. Model. Mechanobiol 19, 317-334. Epub 2019 Sep 10. doi:10.1007/s10237-019-01213-6

Maraldi, T., Riccio, M., Resca, E., Pisciotta, A., La Sala, G. B., Ferrari, A., et al. (2011). Human Amniotic Fluid Stem Cells Seeded in Fibroin Scaffold Produce In Vivo Mineralized Matrix. Tissue Eng. Part A 17, 2833-2843. Epub 2011 Aug 24. doi:10.1089/ten.tea.2011.0062

Mendes, L. F., Katagiri, H., Tam, W. L., Chai, Y. C., Geris, L., Roberts, S. J., et al. (2018). Advancing Osteochondral Tissue Engineering: Bone Morphogenetic Protein, Transforming Growth Factor, and Fibroblast Growth Factor Signaling Drive Ordered Differentiation of Periosteal Cells Resulting in Stable Cartilage and Bone Formation In Vivo. Stem Cell Res Ther 9, 42. doi:10.1186/s13287-0180787-3

Mohan, N., Gupta, V., Sridharan, B. P., Mellott, A. J., Easley, J. T., Palmer, R. H., et al. (2015). Microsphere-based Gradient Implants for Osteochondral Regeneration: a Long-Term Study in Sheep. Regenerative Med. 10, 709-728. doi:10.2217/rme.15.38

More, N., and Kapusetti, G. (2017). Piezoelectric Material - A Promising Approach for Bone and Cartilage Regeneration. Med. Hypotheses 108, 10-16. Epub 2017 Jul 25. doi:10.1016/j.mehy.2017.07.021

Morgan, E. F., Unnikrisnan, G. U., and Hussein, A. I. (2018). Bone Mechanical Properties in Healthy and Diseased States. Annu. Rev. Biomed. Eng. 20, 119-143. doi:10.1146/annurev-bioeng-062117-121139

Mow, V. C., Ratcliffe, A., and Robin Poole, A. (1992). Cartilage and Diarthrodial Joints as Paradigms for Hierarchical Materials and Structures. Biomaterials 13, 67-97. doi:10.1016/0142-9612(92)90001-5

Mrosek, E. H., Chung, H.-W., Fitzsimmons, J. S., O’Driscoll, S. W., Reinholz, G. G., and Schagemann, J. C. (2016). Porous Tantalum Biocomposites for Osteochondral Defect Repair. Bone Jt. Res. 5, 403-411. doi:10.1302/20463758.59.BJR-2016-000.R110.1302/2046-3758.59.bjr-2016-0070.r1

Murata, D., Fujimoto, R., and Nakayama, K. (2020). Osteochondral Regeneration Using Adipose Tissue-Derived Mesenchymal Stem Cells. Ijms 21, 3589. doi:10.3390/ijms21103589

Murphy, L., and Helmick, C. G. (2012). The Impact of Osteoarthritis in the United States. Am. J. Nurs. 112, S13-S19. doi:10.1097/ 01.NAJ.0000412646.80054.21

Naahidi, S., Jafari, M., Logan, M., Wang, Y., Yuan, Y., Bae, H., et al. (2017). Biocompatibility of Hydrogel-Based Scaffolds for Tissue Engineering Applications. Biotechnol. Adv. 35, 530-544. Epub 2017 May 27. doi:10.1016/ j.biotechadv.2017.05.006

Natarajan, A. B. M., Sivadas, V. P. D., and Nair, P. D. P. D. (2021). 3D-printed Biphasic Scaffolds for the Simultaneous Regeneration of Osteochondral Tissues. Biomed. Mater. 16, 054102. doi:10.1088/1748-605X/ac14cb

Nover, A. B., Lee, S. L., Georgescu, M. S., Howard, D. R., Saunders, R. A., Yu, W. T., et al. (2015). Porous Titanium Bases for Osteochondral Tissue Engineering. Acta Biomater. 27, 286-293. Epub 2015 Aug 28. doi:10.1016/ j.actbio.2015.08.045

Nukavarapu, S. P., and Dorcemus, D. L. (2013). Osteochondral Tissue Engineering: Current Strategies and Challenges. Biotechnol. Adv. 31, 706-721. Epub 2012 Nov 19. doi:10.1016/j.biotechadv.2012.11.004

Paggi, C. A., Venzac, B., Karperien, M., Leijten, J. C. H., and Le Gac, S. (2020). Monolithic Microfluidic Platform for Exerting Gradients of Compression on Cell-Laden Hydrogels, and Application to a Model of the Articular Cartilage. Sensors Actuators B: Chem. 315, 127917. doi:10.1016/ j.snb.2020.127917

Pan, J., Zhou, X., Li, W., Novotny, J. E., Doty, S. B., and Wang, L. (2009). In Situ measurement of Transport between Subchondral Bone and Articular Cartilage. J. Orthop. Res. 27, 1347-1352. doi:10.1002/jor.20883
Pina, S., Rebelo, R., Correlo, V. M., Oliveira, J. M., and Reis, R. L. (2018). Bioceramics for Osteochondral Tissue Engineering and Regeneration. Adv. Exp. Med. Biol. 1058, 53-75. doi:10.1007/978-3-319-76711-6_3

Pirosa, A., Gottardi, R., Alexander, P. G., Puppi, D., Chiellini, F., and Tuan, R. S. (2021). An In Vitro Chondro-Osteo-Vascular Triphasic Model of the Osteochondral Complex. Biomaterials 272, 120773, 2021 . Epub $2021 \mathrm{Mar}$ 22. doi:10.1016/j.biomaterials.2021.120773

Poole, C. A., Flint, M. H., and Beaumont, B. W. (1987). Chondrons in Cartilage: Ultrastructural Analysis of the Pericellular Microenvironment in Adult Human Articular Cartilages. J. Orthop. Res. 5, 509-522. doi:10.1002/jor.1100050406

Prasanna, S. J., Gopalakrishnan, D., Shankar, S. R., and Vasandan, A. B. (2010). Pro-Inflammatory Cytokines, IFN $\gamma$ and TNF $\alpha$, Influence Immune Properties of Human Bone Marrow and Wharton Jelly Mesenchymal Stem Cells Differentially. PLoS One 5, e9016. doi:10.1371/journal.pone.0009016

Qin, H., Zhu, C., An, Z., Jiang, Y., Zhao, Y., Wang, J., et al. (2014). Silver Nanoparticles Promote Osteogenic Differentiation of Human Urine-Derived Stem Cells at Noncytotoxic Concentrations. Ijn 9, 2469-2478. doi:10.2147/IJN.S59753

Raeisdasteh Hokmabad, V., Davaran, S., Ramazani, A., and Salehi, R. (2017). Design and Fabrication of Porous Biodegradable Scaffolds: a Strategy for Tissue Engineering. J. Biomater. Sci. Polym. Edition 28, 1797-1825. doi:10.1080/ 09205063.2017.1354674

Raucci, M. G., Demitri, C., Soriente, A., Fasolino, I., Sannino, A., and Ambrosio, L. (2018). Gelatin/nano-hydroxyapatite Hydrogel Scaffold Prepared by Sol-Gel Technology as Filler to Repair Bone Defects. J. Biomed. Mater. Res. 106, 2007-2019. Epub 2018 Apr 17. doi:10.1002/jbm.a.36395

Redman, S., Oldfield, S. F., Oldfield, S., and Archer, C. (2005). Current Strategies for Articular Cartilage Repair. eCM 9, 23-32. doi:10.22203/ecm.v009a04

Re'em, T., Witte, F., Willbold, E., Ruvinov, E., and Cohen, S. (2012). Simultaneous Regeneration of Articular Cartilage and Subchondral Bone Induced by Spatially Presented TGF-Beta and BMP-4 in a Bilayer Affinity Binding System. Acta Biomater. 8, 3283-3293. Epub 2012 May 19. doi:10.1016/j.actbio.2012.05.014

Ren, X., Wang, F., Chen, C., Gong, X., Yin, L., and Yang, L. (2016). Engineering Zonal Cartilage through Bioprinting Collagen Type II Hydrogel Constructs with Biomimetic Chondrocyte Density Gradient. BMC Musculoskelet. Disord. 17, 301. doi:10.1186/s12891-016-1130-8

Responte, D. J., Natoli, R. M., and Athanasiou, K. A. (2007). Collagens of Articular Cartilage: Structure, Function, and Importance in Tissue Engineering. Crit. Rev. Biomed. Eng. 35, 363-411. doi:10.1615/critrevbiomedeng.v35.i5.20

Reyes, R., Delgado, A., Solis, R., Sanchez, E., Hernandez, A., Roman, J. S., et al. (2014). Cartilage Repair by Local Delivery of Transforming Growth Factor-B1 or Bone Morphogenetic Protein-2 from a Novel, Segmented Polyurethane/ polylactic-Co -glycolic Bilayered Scaffold. J. Biomed. Mater. Res. 102, 1110-1120. Epub 2013 Jun 14. doi:10.1002/jbma.3476910.1002/jbm.a.34769

Ribeiro, V. P., Pina, S., Costa, J. B., Cengiz, I. F., García-Fernández, L., FernándezGutiérrez, M. d. M., et al. (2019). Enzymatically Cross-Linked Silk FibroinBased Hierarchical Scaffolds for Osteochondral Regeneration. ACS Appl. Mater. Inter. 11, 3781-3799. Epub 2019 Jan 16. doi:10.1021/acsami.8b21259

Sadtler, K., Singh, A., Wolf, M. T., Wang, X., Pardoll, D. M., and Elisseeff, J. H. (2016). Design, Clinical Translation and Immunological Response of Biomaterials in Regenerative Medicine. Nat. Rev. Mater. 1, 16040. doi:10.1038/natrevmats.2016.40

Salonius, E., Muhonen, V., Lehto, K., Järvinen, E., Pyhältö, T., Hannula, M., et al. (2019). Gas-foamed Poly(lactide-co-glycolide) and Poly(lactide-co-glycolide) with Bioactive Glass Fibres Demonstrate Insufficient Bone Repair in Lapine Osteochondral Defects. J. Tissue Eng. Regen. Med. 13, 406-415. Epub 2019 Feb 18. doi:10.1002/term.2801

Sasaki, A., Mizuno, M., Ozeki, N., Katano, H., Otabe, K., Tsuji, K., et al. (2018). Canine Mesenchymal Stem Cells from Synovium Have a Higher Chondrogenic Potential Than Those from Infrapatellar Fat Pad, Adipose Tissue, and Bone Marrow. PLoS One 13, e0202922. doi:10.1371/journal.pone.0202922

Schaefer, D., Martin, I., Shastri, P., Padera, R. F., Langer, R., Freed, L. E., et al. (2000). In Vitro generation of Osteochondral Composites. Biomaterials 21, 2599-2606. doi:10.1016/s0142-9612(00)00127-7

Schlesinger, P. H., Blair, H. C., Beer Stolz, D., Riazanski, V., Ray, E. C., Tourkova, I. L., et al. (2020). Cellular and Extracellular Matrix of Bone, with Principles of Synthesis and Dependency of mineral Deposition on Cell Membrane 
Transport. Am. J. Physiology-Cell Physiol. 318, C111-C124. Epub 2019 Sep 18. doi:10.1152/ajpcell.00120.2019

Schmidt-Rohlfing, B., Schneider, U., Goost, H., and Silny, J. (2002). Mechanically Induced Electrical Potentials of Articular Cartilage. J. Biomech. 35, 475-482. doi:10.1016/s0021-9290(01)00232-9

Sempertegui, N. D., Narkhede, A. A., Thomas, V., and Rao, S. S. (2018). A Combined Compression Molding, Heating, and Leaching Process for Fabrication of Micro-porous Poly( $\varepsilon$-Caprolactone) Scaffolds. J. Biomater. Sci. Polym. Edition 29, 1978-1993. Epub 2018 Oct 30. doi:10.1080/ 09205063.2018.1498719

Seo, J.-p., Tanabe, T., Tsuzuki, N., Haneda, S., Yamada, K., Furuoka, H., et al. (2013). Effects of Bilayer Gelatin/ $\beta$-Tricalcium Phosphate Sponges Loaded with Mesenchymal Stem Cells, Chondrocytes, Bone Morphogenetic Protein-2, and Platelet Rich Plasma on Osteochondral Defects of the Talus in Horses. Res. Vet. Sci. 95, 1210-1216. Epub 2013 Sep 5. doi:10.1016/j.rvsc.2013.08.016

Seong, J. M., Kim, B.-C., Park, J.-H., Kwon, I. K., Mantalaris, A., and Hwang, Y.-S. (2010). Stem Cells in Bone Tissue Engineering. Biomed. Mater. 5, 062001, 2010. Epub 2010 Oct 6. doi:10.1088/1748-6041/5/6/062001

Shalumon, K., Sheu, C., Fong, Y., Liao, H.-T., and Chen, J.-P. (2016). Microsphere-Based Hierarchically Juxtapositioned Biphasic Scaffolds Prepared from Poly(Lactic-Co-Glycolic Acid) and Nanohydroxyapatite for Osteochondral Tissue Engineering. Polymers 8, 429. doi:10.3390/ polym8120429

Shao, G., Hanaor, D. A. H., Shen, X., and Gurlo, A. (2020). Freeze Casting: From Low-Dimensional Building Blocks to Aligned Porous Structures-A Review of Novel Materials, Methods, and Applications. Adv. Mater. 32, 1907176, 2020 . Epub 2020 Mar 12. doi:10.1002/adma.201907176

Sheehy, E. J., Buckley, C. T., and Kelly, D. J. (2012). Oxygen Tension Regulates the Osteogenic, Chondrogenic and Endochondral Phenotype of Bone Marrow Derived Mesenchymal Stem Cells. Biochem. Biophysical Res. Commun. 417, 305-310. Epub 2011 Dec 1. doi:10.1016/j.bbrc.2011.11.105

Sieber, S., Michaelis, M., Gühring, H., Lindemann, S., and Gigout, A. (2020). Importance of Osmolarity and Oxygen Tension for Cartilage Tissue Engineering. BioResearch Open Access 9, 106-115. doi:10.1089/ biores.2020.0009

Sing, S. L., Wang, S., Agarwala, S., Wiria, F. E., Ha, T. M. H., and Yeong, W. Y. (2017). Fabrication of Titanium Based Biphasic Scaffold Using Selective Laser Melting and Collagen Immersion. Int. J. Bioprint 3, 007. doi:10.18063/ IIB.2017.01.007

Singh, A., Bivalacqua, T. J., and Sopko, N. (2018). Urinary Tissue Engineering: Challenges and Opportunities. Sex. Med. Rev. 6, 35-44. Epub 2017 Oct 21. doi:10.1016/j.sxmr.2017.08.004

Smith, B. D., and Grande, D. A. (2015). The Current State of Scaffolds for Musculoskeletal Regenerative Applications. Nat. Rev. Rheumatol. 11, 213-222. doi:10.1038/nrrheum.2015.27

Sophia Fox, A. J., Bedi, A., and Rodeo, S. A. (2009). The Basic Science of Articular Cartilage: Structure, Composition, and Function. Sports Health 1, 461-468. doi:10.1177/1941738109350438

Sun, Y., Deng, W., Yao, G., Chen, W., Tang, X., Feng, X., et al. (2018). Citrullinated Fibrinogen Impairs Immunomodulatory Function of Bone Marrow Mesenchymal Stem Cells by Triggering Toll-like Receptor. Clin. Immunol. 193, 38-45. Epub 2018 Jan 31. doi:10.1016/j.clim.2018.01.008

Suzuki, A., Minamide, M., Iwaya, C., Ogata, K., and Iwata, J. (2020). Role of Metabolism in Bone Development and Homeostasis. Ijms 21, 8992. doi:10.3390/ijms21238992

Tamjid, E., Bohlouli, M., Mohammadi, S., Alipour, H., and Nikkhah, M. (2020). Sustainable Drug Release from Highly Porous and Architecturally Engineered Composite Scaffolds Prepared by 3D Printing. J. Biomed. Mater. Res. 108, 1426-1438. Epub 2020 Mar 10. doi:10.1002/jbm.a.36914

Tang, D., Tare, R. S., Yang, L.-Y., Williams, D. F., Ou, K.-L., and Oreffo, R. O. C. (2016). Biofabrication of Bone Tissue: Approaches, Challenges and Translation for Bone Regeneration. Biomaterials 83, 363-382. Epub 2016 Jan 9. doi:10.1016/ j.biomaterials.2016.01.024

Tourné-Péteilh, C., Robin, B., Lions, M., Martinez, J., Mehdi, A., Subra, G., et al. (2019). Combining Sol-Gel and Microfluidics Processes for the Synthesis of Protein-Containing Hybrid Microgels. Chem. Commun. 55, 13112-13115. doi:10.1039/c9cc04963k
Valot, L., Maumus, M., Montheil, T., Martinez, J., Noël, D., Mehdi, A., et al. (2019). Biocompatible Glycine-Assisted Catalysis of the Sol-Gel Process: Development of Cell-Embedded Hydrogels. Chempluschem 84, 1720-1729. Epub 2019 Oct 24. doi:10.1002/cplu.201900509

Varela-Eirin, M., Loureiro, J., Fonseca, E., Corrochano, S., Caeiro, J. R., Collado, M., et al. (2018). Cartilage Regeneration and Ageing: Targeting Cellular Plasticity in Osteoarthritis. Ageing Res. Rev. 42, 56-71. Epub 2017 Dec 16. doi:10.1016/ j.arr.2017.12.006

Vasquez-Sancho, F., Abdollahi, A., Damjanovic, D., and Catalan, G. (2018). Flexoelectricity in Bones. Adv. Mater. 30, 1705316, 2018 . Epub 2018 Jan 18. doi:10.1002/adma.201705316

Wang, D., Nawabi, D. H., Krych, A. J., Jones, K. J., Nguyen, J., Elbuluk, A. M., et al. (2020). Synthetic Biphasic Scaffolds versus Microfracture for Articular Cartilage Defects of the Knee: A Retrospective Comparative Study. Cartilage. Epub ahead of print. doi:10.1177/1947603520903418

Wang, F., Ying, Z., Duan, X., Tan, H., Yang, B., Guo, L., et al. (2009). Histomorphometric Analysis of Adult Articular Calcified Cartilage Zone. J. Struct. Biol. 168, 359-365. Epub 2009 Aug 31. doi:10.1016/j.jsb.2009.08.010

Wei, W., and Dai, H. (2021). Articular Cartilage and Osteochondral Tissue Engineering Techniques: Recent Advances and Challenges. Bioactive Mater. 6, 4830-4855. doi:10.1016/j.bioactmat.2021.05.011

Wingender, B., Ni, Y., Zhang, Y., Taylor, C., and Gower, L. (2018). Hierarchical Characterization and Nanomechanical Assessment of Biomimetic Scaffolds Mimicking Lamellar Bone via Atomic Force Microscopy Cantilever-Based Nanoindentation. Materials 11, 1257. doi:10.3390/ma11071257

Wu, X., Zhou, M., Jiang, F., Yin, S., Lin, S., Yang, G., et al. (2021). Marginal Sealing Around Integral Bilayer Scaffolds for Repairing Osteochondral Defects Based on Photocurable Silk Hydrogels. Bioactive Mater. 6, 3976-3986. doi:10.1016/ j.bioactmat.2021.04.005

Xu, D., Cheng, G., Dai, J., and Li, Z. (2021). Bi-layered Composite Scaffold for Repair of the Osteochondral Defects. Adv. Wound Care 10, 401-414. doi:10.1089/wound.2019.1140

Xuan, H., Hu, H., Geng, C., Song, J., Shen, Y., Lei, D., et al. (2020). Biofunctionalized Chondrogenic Shape-Memory Ternary Scaffolds for Efficient Cell-free Cartilage Regeneration. Acta Biomater. 105, 97-110. Epub 2020 Jan 15. doi:10.1016/j.actbio.2020.01.015

Yao, Q., Nooeaid, P., Detsch, R., Roether, J. A., Dong, Y., Goudouri, O.-M., et al. (2014). Bioglass/chitosan-polycaprolactone Bilayered Composite Scaffolds Intended for Osteochondral Tissue Engineering. J. Biomed. Mater. Res. 102, a-n. Epub 2014 Feb 26. doi:10.1002/jbm.a.35125

Ye, K., Traianedes, K., Robins, S. A., Choong, P. F. M., and Myers, D. E. (2018). Osteochondral Repair Using an Acellular Dermal Matrix-Pilot In Vivo Study in a Rabbit Osteochondral Defect Model. J. Orthop. Res. 36, 1919-1928. Epub 2018 Jan 24. doi:10.1002/jor.23837

Yin, H., Wang, Y., Sun, X., Cui, G., Sun, Z., Chen, P., et al. (2018). Functional Tissue-Engineered Microtissue Derived from Cartilage Extracellular Matrix for Articular Cartilage Regeneration. Acta Biomater. 77, 127-141. Epub 2018 Jul 18. doi:10.1016/j.actbio.2018.07.031

Yunos, D., Ahmad, Z., Salih, V., and Boccaccini, A. (2013). Stratified Scaffolds for Osteochondral Tissue Engineering Applications: Electrospun PDLLA Nanofibre Coated Bioglass-Derived Foams. J. Biomater. Appl. 27, 537-551. doi:10.1177/0885328211414941

Zaborowska, M., Bodin, A., Bäckdahl, H., Popp, J., Goldstein, A., and Gatenholm, P. (2010). Microporous Bacterial Cellulose as a Potential Scaffold for Bone Regeneration. Acta Biomater. 6, 2540-2547. Epub 2010 Jan 11. doi:10.1016/ j.actbio.2010.01.004

Zha, K., Li, X., Yang, Z., Tian, G., Sun, Z., Sui, X., et al. (2021). Heterogeneity of Mesenchymal Stem Cells in Cartilage Regeneration: from Characterization to Application. NPJ Regen. Med. 6, 14. doi:10.1038/s41536-021-00122-6

Zhang, B., Huang, J., and Narayan, R. J. (2020). Gradient Scaffolds for Osteochondral Tissue Engineering and Regeneration. J. Mater. Chem. B 8, 8149-8170. doi:10.1039/d0tb00688b

Zhang, J., Liu, H., Ding, J.-X., Wu, J., Zhuang, X.-L., Chen, X.-S., et al. (2016). HighPressure Compression-Molded Porous Resorbable Polymer/Hydroxyapatite Composite Scaffold for Cranial Bone Regeneration. ACS Biomater. Sci. Eng. 2, 1471-1482. Epub 2016 Aug 10. doi:10.1021/acsbiomaterials.6b00202

Zhang, J., Zhang, X., Hong, Y., Fu, Q., He, Q., Mechakra, A., et al. (2020). TissueAdhesive Paint of Silk Microparticles for Articular Surface Cartilage 
Regeneration. ACS Appl. Mater. Inter. 12, 22467-22478. Epub 2020 May 12. doi:10.1021/acsami.0c01776

Zhang, S., Chen, L., Jiang, Y., Cai, Y., Xu, G., Tong, T., et al. (2013). Bi-layer Collagen/microporous Electrospun Nanofiber Scaffold Improves the Osteochondral Regeneration. Acta Biomater. 9, 7236-7247. Epub 2013 Apr 6. doi:10.1016/j.actbio.2013.04.003

Zhang, S., Chuah, S. J., Lai, R. C., Hui, J. H. P., Lim, S. K., and Toh, W. S. (2018). MSC Exosomes Mediate Cartilage Repair by Enhancing Proliferation, Attenuating Apoptosis and Modulating Immune Reactivity. Biomaterials 156, 16-27. Epub 2017 Nov 21. doi:10.1016/j.biomaterials.2017.11.028

Zhang, Y.-t., Niu, J., Wang, Z., Liu, S., Wu, J., and Yu, B. (2017). Repair of Osteochondral Defects in a Rabbit Model Using Bilayer Poly(Lactide-CoGlycolide) Scaffolds Loaded with Autologous Platelet-Rich Plasma. Med. Sci. Monit. 23, 5189-5201. doi:10.12659/msm.904082

Zhang, Y., McNeill, E., Tian, H., Soker, S., Andersson, K.-E., Yoo, J. J., et al. (2008). Urine Derived Cells Are a Potential Source for Urological Tissue Reconstruction. J. Urol. 180, 2226-2233. Epub 2008 Sep 20. doi:10.1016/j.juro.2008.07.023

Zhao, X., Shah, D., Gandhi, K., Wei, W., Dwibedi, N., Webster, L., et al. (2019). Clinical, Humanistic, and Economic burden of Osteoarthritis Among Noninstitutionalized Adults in the United States. Osteoarthritis and Cartilage 27, 1618-1626. Epub 2019 Jul 9. doi:10.1016/j.joca.2019.07.002

Zheng, Y.-L., Sun, Y.-P., Zhang, H., Liu, W.-J., Jiang, R., Li, W.-Y., et al. (2015). Mesenchymal Stem Cells Obtained from Synovial Fluid Mesenchymal Stem Cell-Derived Induced Pluripotent Stem Cells on a Matrigel Coating Exhibited Enhanced Proliferation and Differentiation Potential. PLoS One 10, e0144226. doi:10.1371/journal.pone.0144226

Zhou, F., Hong, Y., Zhang, X., Yang, L., Li, J., Jiang, D., et al. (2018). Tough Hydrogel with Enhanced Tissue Integration and In Situ Forming Capability for
Osteochondral Defect Repair. Appl. Mater. Today 13, 32-44. doi:10.1016/ j.apmt.2018.08.005

Zhou, L., Gjvm, V. O., Malda, J., Stoddart, M. J., Lai, Y., Richards, R. G., et al. (2020). Innovative Tissue-Engineered Strategies for Osteochondral Defect Repair and Regeneration: Current Progress and Challenges. Adv. Healthc. Mater. 9, 2001008, 2020 . Epub ahead of print. doi:10.1002/adhm.202001008 Zhu, M., He, X., Xin, C., Zhu, Y., and Liu, Z. (2020). 3D Printing of an Integrated Triphasic MBG-Alginate Scaffold with Enhanced Interface Bonding for Hard Tissue Applications. J. Mater. Sci. Mater. Med. 31, 113. doi:10.1007/s10856020-06459-6

Conflict of Interest: The authors declare that the research was conducted in the absence of any commercial or financial relationships that could be construed as a potential conflict of interest.

Publisher's Note: All claims expressed in this article are solely those of the authors and do not necessarily represent those of their affiliated organizations, or those of the publisher, the editors and the reviewers. Any product that may be evaluated in this article, or claim that may be made by its manufacturer, is not guaranteed or endorsed by the publisher.

Copyright $\odot 2022 \mathrm{Fu}$, Wang, Yang, Chen, Zhang, Deng, Zhang, Yu and Yuan. This is an open-access article distributed under the terms of the Creative Commons Attribution License (CC BY). The use, distribution or reproduction in other forums is permitted, provided the original author(s) and the copyright owner(s) are credited and that the original publication in this journal is cited, in accordance with accepted academic practice. No use, distribution or reproduction is permitted which does not comply with these terms. 